\title{
Exploring the high-temperature kinetics of diethyl carbonate (DEC) under pyrolysis and flame conditions
}

\author{
${ }^{\mathrm{a}}$ Wenyu Sun, ${ }^{\mathrm{a}}$ Can Huang, ${ }^{\mathrm{a}}$ Tao Tao, ${ }^{\mathrm{b}}$ Feng Zhang, ${ }^{\mathrm{b}}$ Wei Li,${ }^{\mathrm{c}}$ Nils Hansen, ${ }^{\mathrm{a}}$ Bin Yang ${ }^{*}$ \\ ${ }^{a}$ Center for Combustion Energy and Department of Thermal Engineering, Tsinghua University, Beijing 100084, PR \\ China \\ ${ }^{b}$ National Synchrotron Radiation Laboratory, University of Science and Technology of China, Hefei, Anhui 230029, \\ PR China \\ ${ }^{c}$ Combustion Research Facility, Sandia National Laboratories, Livermore, CA 94551, USA
}

\begin{abstract}
To pursue insights into the high-temperature kinetics of diethyl carbonate (DEC), a potential clean oxygenated additive for diesel fuels, a systematical kinetic investigation was carried out in this work. Species mole fraction variations were recorded by a gas chromatography (GC) system during the pyrolysis of DEC in a flow reactor under three different pressures $(30,150$ and 780 Torr). And quantitative measurements were conducted for over thirty species in a fuel-rich $(\phi=1.5)$ premixed $\mathrm{DEC} / \mathrm{O}_{2} /$ argon flame using synchrotron vacuum ultraviolet photoionization mass spectrometry. Pressure-dependent rate coefficients for DEC unimolecular decompositions were obtained with RRKM/master equation calculations. A kinetic model for DEC high-temperature pyrolysis and combustion was developed employing the calculated kinetic parameters, which could well predict all available measurements. Model analysis revealed that a two-step molecular elimination pathway exclusively led to the fuel decomposition under pyrolysis conditions, while in the premixed flame the fuel was consumed mainly by hydrogen abstractions from the secondary carbon atoms. The pyrolysis and combustion behaviors of DEC were compared with those of dimethyl carbonate (DMC), a simpler homologue of DEC, under similar conditions. It was found that DEC was of less thermal stability during the pyrolysis and that $\mathrm{C}_{2}$ intermediates were of much higher concentrations in the DEC flame. Furthermore, it was found that DEC shared combustion characteristics with some other oxygenated fuels possessing specific common structural features.
\end{abstract}

Keywords: Diethyl carbonate (DEC); Pyrolysis; Premixed flame; Kinetic model; Oxygenated fuels

${ }^{*}$ Corresponding author. Fax: + 861062796631.

E-mail address: byang@tsinghua.edu.cn (B.Yang). 


\section{Introduction}

Oxygenated fuels produced from renewable biological resources can potentially offer an effective solution to the concern-arousing environmental issue caused by the combustion of fossil fuels $[1,2]$. Extensive studies have been devoted to various oxygenated fuels, including alcohols, esters, and ethers, with respects to both engine performances and fundamental combustion chemistry. Recently, carbonates including dimethyl carbonate (DMC) and diethyl carbonate (DEC) (see the chemical structures in Scheme 1) have drawn increasing interest in the combustion community [3-6]. As an oxygenated additive, DEC is easily miscible with diesel fuels without phase separation and its decomposition products [carbon dioxide $\left(\mathrm{CO}_{2}\right)$ and ethanol $\left(\mathrm{C}_{2} \mathrm{H}_{5} \mathrm{OH}\right)$ ] do little harm to the environment [7]. Besides, by the same mass it can release more heat in the combustion process than its simpler homologue DMC (21.1 and 13.5 MJ/kg for DEC and DMC, respectively [8]). After testing a total of 11 oxygenated diesel additives in practical engine conditions, Kozak et al. [9] concluded that DEC is the most effective one with regard to particle matter (PM) reduction and it allows for a substantial improvement in the $\mathrm{PM} / \mathrm{NO}_{\mathrm{x}}$ trade-off. Furthermore, it is inspiring that a clean approach has been recently proposed for the DEC synthesis by using ethanol $\left(\mathrm{C}_{2} \mathrm{H}_{5} \mathrm{OH}\right)$, a mass-produced biofuel, and $\mathrm{CO}_{2}$ in the presence of a $\mathrm{Cu}-\mathrm{Ni} / \mathrm{Ac}$ catalyst [10].

For such a promising oxygenated fuel as DEC, a kinetic understanding in extensive combustion conditions is necessary for elucidating the mechanism of emissions reduction and for achieving controllable applications. Recently, the oxidation kinetics of DEC was addressed in systematical investigations $[3,4]$. Ignition delay times and species concentrations during DEC oxidation in a jet-stirred reactor (JSR) at elevated pressures and low-to-medium temperatures were measured [3], and in the same work, a detailed kinetic model was proposed and tested. A later work [4] complemented the JSR oxidation experiments at the atmospheric pressure for further model validations, and laminar burning velocities were also experimentally determined to test the model performance at higher temperatures. Though the model could satisfactorily predict the measurements under low-temperature oxidation conditions [3, 4], the high-temperature kinetics has not been sufficiently tested, as only limited global parameters, the laminar burning velocities [4], were available for the model validation. 
In order to extend our understanding on the high temperature kinetics of DEC, continuous efforts

have been made in this work with combined theoretical, experimental and modeling approaches. Specifically, theoretical calculations were performed to acquire pressure-dependent rate coefficients for unimolecular decompositions of DEC and its dominant products. Concentration profiles of the products during DEC pyrolysis at different pressures were obtained using gas chromatography (GC). The chemical structure of a fuel-rich premixed DEC flame was measured with a photoionization molecular-beam mass spectrometer (PI-MBMS). Several modifications, mainly updates of relevant rate coefficients with theoretical results, have been made to the previous model [3]. The updated model, which could satisfactorily predict all high-temperature measurements in this work, was employed to explore the fuel consumption pathways under pyrolysis and combustion conditions. Meanwhile, comparisons were made in aspects of experimental observations and reaction patterns between DEC and DMC, a simpler homologue of DEC with methyl groups on both sides (see Scheme 1), whose combustion kinetics has been investigated under similar conditions [6]. To address some general connections between structural features and combustion characteristics for oxygenated fuels, we further compared the combustion kinetics of DEC with those of other oxygenates possessing the same moieties, including the ethoxy formyl group $\left[\mathrm{CH}_{3} \mathrm{CH}_{2} \mathrm{OC}(=\mathrm{O})-\right]$, the carbonate group [-OC(=O)O-] and the ethoxy group $\left(\mathrm{CH}_{3} \mathrm{CH}_{2} \mathrm{O}-\right)$.

\section{Experimental methods}

\subsection{Flow reactor pyrolysis}

The DEC pyrolysis experiments were performed with the same apparatus as used in our previous study of DMC [6]. The detailed description of the apparatus and the schematic diagram could be referred to previous works $[6,11]$. Briefly, the apparatus is comprised of a pyrolysis chamber, a sampling system, a GC system and a linking transfer line. A crystalline $\alpha$-alumina tube with the inner diameter (ID) of $6.8 \mathrm{~mm}$ and the length of $220 \mathrm{~mm}$ was placed in the center of the chamber and heated by a heating wire. Surface catalyzed reactions could be minimal by adopting this specific material, as discussed in literature [12,13]. Vaporized DEC and the diluent argon (Ar) with respective flow rates of 20 and 980 standard c.c./minute (SCCM) were mixed before entering the flow tube. The pyrolysis products were sampled with a 3-mm-ID quartz tube at the outlet of the tube and then driven to the GC system through the transfer line which was kept at $423 \mathrm{~K}$ to prevent 
condensation. The pyrolysis experiments were conducted at three different pressures, i.e. 30, 150

and 780 Torr. The pressure could be treated as constant along the tube, as confirmed by calculations [14]. An HP-PLOT Q (Agilent Technologies, $30 \mathrm{~m} \times 320 \mu \mathrm{m} \times 20 \mu \mathrm{m}$ ) column which can effectively separate conventional small hydrocarbon and oxygenated species was employed. And an electron ionization mass spectrometer (EI-MS, $70 \mathrm{eV}$ ) was connected to the $\mathrm{GC}$ for species identification while a flame ionization detector (FID) and a thermal conductivity detector (TCD) were used to record the signals. In the conversion of signal intensities to species mole fractions, DEC was taken as the internal standard. A gas mixture with a known composition, consisting of vaporized DEC, vaporized ethanol (a major product) and calibration gases, was used to determine the response factors relative to DEC for separate species. An S-type thermocouple was used to record the temperature distributions along the centerline of the flow tube, each of which was denoted by the corresponding maximum value $\left(T_{\max }\right)$. Species mole fractions at the outlet of the flow tube will be exhibited as functions of $T_{\max }$ in the figures below. The residence time varied with temperature and pressure because the initial total flow rate was kept constant. The calculated values at 30, 150 and 780 Torr in the investigated temperature ranges were $8.4 \times 10^{-3}-1.1 \times 1^{-2}, 4.4-5.5 \times$ $10^{-2}$ and $2.3-2.8 \times 10^{-1} \mathrm{~s}$, respectively. The experimental uncertainty in mole fractions was estimated to be $\pm 5 \%$ for DEC and $\pm 10 \%$ for pyrolysis products. In addition, the error in the temperature measurements was estimated to be within $\pm 30 \mathrm{~K}$.

\subsection{Low-pressure laminar premixed flame}

The flame species measurements were conducted at the Advanced Light Source (ALS) of the Lawrence Berkeley National Laboratory. The apparatus includes a McKenna burner, a molecular beam sampling system and a time-of-flight mass spectrometer (TOFMS) with the synchrotron vacuum ultraviolet (VUV) light being the ionization source, as detailedly described in [15, 16]. A premixed flame of DEC with the equivalence ratio of 1.5 was stabilized on a 6.0 -cm-diameter stainless steel burner. The pressure in the flame chamber was controlled at 25.0 Torr to maximize the flame thickness and the stand-off distance while maintaining flame stability. The total flow rate was kept at 4.000 standard liters per minute (SLM) with 50\% Ar dilution. Gas flow rates (2.000 SLM of Ar and 1.600 SLM of $\mathrm{O}_{2}$ ) were controlled separately by mass flow controllers, while the flow rate of liquid DEC $(2.164 \mathrm{ml} / \mathrm{min})$ into the vaporizer was metered by a syringe pump. Errors 
for all flow rates were estimated within $\pm 2 \%$ of the target values. The flame gases were sampled

along the axis of the flame by a quartz nozzle (with a $40^{\circ}$ included angle and a $200 \mu \mathrm{m}$ orifice at the tip) and then entered the ionization region of the mass spectrometer. The molecular beam was crossed by the dispersed VUV light from the synchrotron, and photo-ions were collected and mass-analyzed by the TOFMS with a mass resolution up to $\mathrm{m} / \Delta \mathrm{m}=400$. Two different operation modes were adopted in the experiment. When the burner was fixed at where signals for most species were of relatively high intensities, the photon energy was scanned to obtain the photoionization efficiency (PIE) spectra for species identification. For example, the PIE curve for $m / z=60$ recorded at photon energies from 9.4 to $11.2 \mathrm{eV}$ is shown in Fig. 1. The threshholds near $9.72 \mathrm{eV}$ and $10.65 \mathrm{eV}$, as indicated by the arrows, reveal the presence of ethyl methyl ether $\left(\mathrm{C}_{2} \mathrm{H}_{5} \mathrm{OCH}_{3}\right)$ [17] and acetic acid $\left(\mathrm{CH}_{3} \mathrm{COOH}\right)$ [18], respectively. By fixing the photon energy while gradually changing the sampling position, the integrated ion intensities for a specific mass were recorded as a function of the distance from the burner surface, which were subsequently converted to species mole fraction profiles by following the practice proposed by Cool et al. [19].

To avoid interferences between the intermediate ions and the fuel fragments with the same $\mathrm{m} / \mathrm{z}$, relative photoionization cross section (PICS) values between fragment ions and the parent fuel ion are needed for signal corrections. Therefore an additional photon energy scan (9.8-11.5 eV) was performed for a cold gas mixture of DEC and Ar. The mass spectrum recorded at the photon energy of $11.5 \mathrm{eV}$ is provided in Fig. S1 in the Supplemental Material, with the PIE curves for the parent ion and predominant fragment ions shown in the inset. According to the measurement, the ionization energy (IE) of DEC is about $10.1 \mathrm{eV}$, and the apperance energies (AEs) for separate fragmentations are also obtained.

The temperature profile was determined according to its relationship with the pressure in the first-stage chamber $\left(p_{1 s t}\right)$ as described by the following equation [20, 21]:

$$
p_{1 s t}=C \sqrt{\frac{\gamma}{\bar{M} \cdot T}}\left(\frac{2}{\gamma+1}\right)^{Z}
$$

with $\mathrm{Z}=(\gamma+1) / 2(\gamma-1) ; \bar{M}$ is the mean molar mass; $\gamma$ is the adiabaticity coefficient $\left(\mathrm{C}_{\mathrm{p}} / \mathrm{C}_{\mathrm{V}}\right)$ and $\mathrm{C}$ is a device-specific constant which can be obtained with the exhaust gas temperature measured at 30.0 $\mathrm{mm}$ using the technique of laser-induced fluorescence (LIF). According to previous works [20, 22] using the same method to derive temperature profiles, the uncertainty in temperature measurements 
was estimated within $\pm 150 \mathrm{~K}$. And regarding the probe position, the accuracy of the "distance from

the burner" was estimated to be $\pm 1 \mathrm{~mm}$. Comprehensive factors bringing in errors in the concentration measurements, which have been addressed in references [23] and [6], were considered to provide the mole fraction uncertainty for each species. Besides, the presence of numerous fuel-fragmentations (see Fig. S1) could result in larger uncertainties. The uncertainty factor $(U F)$ for the major species fractions is estimated to be 1.2 (For the mole fraction $\mathrm{x}$ of a certain species, the uncertainty range is between the upper limit of $\mathrm{x} \cdot U F$ and the lower limit of $\mathrm{x} / U F$, as defined in [5]). The $U F$ is within 1.7 for the stable intermediates with measured PICSs, while it can be as large as 2 to 4 for radicals and species with estimated PICSs. The $U F$ s for the peak mole fractions of separate intermediates are provided in Table S1 in the Supplemental Material, together with the PICSs and mass discrimination (MD) factors used in the quantification.

The results for all chemical composition measurements in this work are provided in the Supplemental Material.

\section{Theoretical calculations and kinetic modeling}

\subsection{Theoretical calculations}

Previous studies $[24,25]$ have suggested that an intra-molecular hydrogen transfer [DEC $\rightarrow$ $\left.\mathrm{C}_{2} \mathrm{H}_{5} \mathrm{C}(=\mathrm{O}) \mathrm{OH}+\mathrm{C}_{2} \mathrm{H}_{4}\right]$ is the predominant pathway for DEC unimolecular decomposition. In the previous model [3] the rate coefficient of this important reaction was assigned with the extrapolation of an earlier measurement [26] without considering the pressure-dependence. In the present work, an RRKM/master equation analysis was performed to obtain the rate coefficients for several competing channels of DEC unimolecular decomposition over wide temperature and pressure ranges.

With the help of matrix isolation infrared spectroscopy experiments and theoretical calculations [27], the most stable conformation of DEC has been assigned as the "cc(tt)" structure with a planar backbone and the $C_{2 v}$ symmetry, as shown in Scheme 1. Thus only this conformation was considered neglecting the fast conformational change to reduce computational difficulties. Geometries and rovibrational properties of all stationary points were determined at the B3LYP/cc-pVTZ level, and then single point energies for these structures were obtained with the CCSD(T)-F12/cc-pVTZ-F12 method [28]. The DFT calculations were performed with the Gaussian 
09 program [29] and the CCSD(T)-F12 energies were obtained by the MOLPRO program package

[30]. The master equation analysis was performed with the kinetic code MESS [31] to obtain phenomenological rate coefficients over the temperature range of 500-2500 $\mathrm{K}$ and the pressure range of 0.01-100 atm. The internal rotations of methyl or ethyl groups were treated as 1-dimensional (1-D) hindered rotors, and the symmetrical $\left(\mathrm{CH}_{3} \mathrm{CH}_{2} \ldots \mathrm{O}-\right)$ torsional modes in DEC were treated as a 2-D coupled rotor [31], with the hindrance potentials obtained using relaxed scans at the B3LYP/6-311G(d,p) level. The hindrance potentials for torsional modes in the DEC molecule are provided in Fig. S2. The asymmetric Eckart [32] corrections were incorporated to compensate for the tunneling effects. For the collisional model, interaction between the reactant and the bath gas Ar was modeled by the Lennard-Jones (L-J) potential. The L-J parameters for DEC were correlated with the critical temperature and pressure $\left(\mathrm{T}_{\mathrm{c}}=576.0 \mathrm{~K}, \mathrm{p}_{\mathrm{c}}=33.90\right.$ bar [33]). The collisional energy transfer function was represented by a single-parameter temperature dependent exponential down model with $\left\langle\Delta \mathrm{E}>_{\text {down }}=300 \times(\mathrm{T} / 298)^{0.85} \mathrm{~cm}^{-1}\right.$ which was a reasonable estimation, according to a relevant work for DMC [34].

The potential energy surface (PES) for DEC decomposition, as exhibited in Fig. 2, suggests that the DEC molecule can dissociate through tight transition states (TSa - TSf) with the lowest barriers being $47.3 \mathrm{kcal} / \mathrm{mol}$ to produce $\mathrm{C}_{2} \mathrm{H}_{5} \mathrm{OC}(=\mathrm{O}) \mathrm{OH}$ and $\mathrm{C}_{2} \mathrm{H}_{4}(\mathrm{R} 1)$. The other two energetically favored channels are a six-centered hydrogen transfer involving the two ethoxy $\left(\mathrm{CH}_{3} \mathrm{CH}_{2} \mathrm{O}-\right)$ oxygen atoms leading to $\mathrm{C}_{2} \mathrm{H}_{5} \mathrm{OH}, \mathrm{C}_{2} \mathrm{H}_{4}$ and $\mathrm{CO}_{2}(\mathrm{R} 2)$ and a ethyl $\left(\mathrm{C}_{2} \mathrm{H}_{5}\right)$ transfer through a four-membered transition state producing diethyl ether $\left(\mathrm{C}_{2} \mathrm{H}_{5} \mathrm{OC}_{2} \mathrm{H}_{5}\right)$ and $\mathrm{CO}_{2}(\mathrm{R} 3)$, with barriers of 59.9 and $67.4 \mathrm{kcal} / \mathrm{mol}$ respectively. Three direct bond fission paths exist, but with bond dissociation energies (BDEs) more than $40 \mathrm{kcal} / \mathrm{mol}$ higher than R1, which are thus not competitive. For the leading channels of DEC decompositions, calculated rate coefficients at $0.01 \mathrm{~atm}, 1 \mathrm{~atm}$ and HPL are shown in Fig. S3, while other reactions take negligible branching ratios of less than $2 \%$ under all investigated conditions. It can be seen that R1 is of exclusive dominance, while R2 and R3 become more important with increasing temperatures and pressures, but still much less competitive compared to R1.

Previous studies $[24,25]$ pointed out that $\mathrm{C}_{2} \mathrm{H}_{5} \mathrm{OC}(=\mathrm{O}) \mathrm{OH}$, the product of $\mathrm{R} 1$, would rapidly break down into $\mathrm{C}_{2} \mathrm{H}_{5} \mathrm{OH}$ and $\mathrm{CO}_{2}$ rather than being stabilized. Kinetic parameters for the thermal 
decomposition of $\mathrm{C}_{2} \mathrm{H}_{5} \mathrm{OC}(=\mathrm{O}) \mathrm{OH}$ were also obtained by using the same theoretical methods

mentioned above. Two competing channels respectively leading to $\mathrm{C}_{2} \mathrm{H}_{5} \mathrm{OH}+\mathrm{CO}_{2}$ and carbonic acid $[\mathrm{HOC}(=\mathrm{O}) \mathrm{OH}]+\mathrm{C}_{2} \mathrm{H}_{4}$ were considered and the details were provided in the Supplemental Material.

\subsection{Kinetic modeling}

The kinetic model was modified based on the high-temperature part of a model proposed in [3]. Updated rate coefficients for some important reactions are listed in Table 1. The entire model, including the kinetic, thermochemical and transport files, is provided in the Supplemental Material.

As mentioned above, channels marked in red in Fig. 2 (R1-R3 in Table 1) are of kinetic importance in DEC unimolecular decomposition, which are included in the current model with our computational rate coefficients. The unimolecular dissociations of $\mathrm{C}_{2} \mathrm{H}_{5} \mathrm{OC}(=\mathrm{O}) \mathrm{OH}$, whose kinetic parameters were also theoretically derived in this study, are also integrated to the model as R4-R6. In addition, for the product of $\mathrm{R} 3$, diethyl ether $\left(\mathrm{C}_{2} \mathrm{H}_{5} \mathrm{OC}_{2} \mathrm{H}_{5}, \mathrm{DEE}\right)$, the consumption reactions (Sub 1) were taken from a recently-reported model [35] which has been comprehensively validated. In the previous model [3], the rate coefficients for hydrogen abstractions by $\mathrm{OH}$ and $\mathrm{HO}_{2}$ were determined by analogies to the same type of reactions for ethyl esters [36, 37]. In order to assign the rate coefficients for hydrogen abstractions by other radicals, the rate rules for alkanes were used [3]. Under flame conditions, hydrogen abstractions by the $\mathrm{H}$ atom become more important at higher temperatures. The theoretical rate coefficients have been recently reported [38] for those reactions of ethyl esters which share a lot of structural similarities with DEC. Those calculated results for hydrogen abstractions from the primary and secondary carbon atoms in the ethoxy moiety $\left(\mathrm{CH}_{3} \mathrm{CH}_{2} \mathrm{O}-\right)$ [38] were therefore adopted in the DEC sub-mechanism with the A factors multiplied by two, regarding to the symmetrical structure of DEC.

As exhibited in the preceding section, the intermediate pair sharing the same mass number of $m / z=60, \mathrm{CH}_{3} \mathrm{COOH}$ and $\mathrm{C}_{2} \mathrm{H}_{5} \mathrm{OCH}_{3}$, were unambiguously detected in our experiments. Both species are of non-negligible levels but not included in the previous model [3], so relevant sub-mechanisms were added. Emission of $\mathrm{CH}_{3} \mathrm{COOH}$ in flame conditions has attracted experimental and modeling efforts $[39,40]$ to reveal the formation mechanism. A 
recently-published $\mathrm{CH}_{3} \mathrm{COOH}$ mechanism (Sub 2) [41] was integrated into our kinetic model. The

consumption pathways of $\mathrm{CH}_{3} \mathrm{COOH}$ were validated against measurements of laminar burning velocities and a premixed flame structure by Christensen and Konnov [41]. However, the updated model with only including the $\mathrm{CH}_{3} \mathrm{COOH}$ mechanism adopted from [41] significantly under-predicts the measured $\mathrm{CH}_{3} \mathrm{COOH}$ concentrations in our DEC flame. Thus a potential pathway for $\mathrm{CH}_{3} \mathrm{COOH}$ formation from acetaldehyde $\left(\mathrm{CH}_{3} \mathrm{CHO}\right)$ and $\mathrm{OH}$ (R9) was added to improve the model prediction. The $\mathrm{OH}+\mathrm{CH}_{3} \mathrm{CHO}$ system was investigated with the method of pulsed laser photolysis and the channel leading to $\mathrm{H}+\mathrm{CH}_{3} \mathrm{COOH}$ was proposed according to relevant observations [42]. This reaction has never been considered in previous models, which could however account for the formation of $\mathrm{CH}_{3} \mathrm{COOH}$ under the conditions of abundant $\mathrm{CH}_{3} \mathrm{CHO}$. More theoretical work is needed in exploring the formation pathways of $\mathrm{CH}_{3} \mathrm{COOH}$ in flame conditions with accurate kinetic parameters. A recombination of $\mathrm{CH}_{3} \mathrm{O}$ and $\mathrm{C}_{2} \mathrm{H}_{5}$ (R10) was included to account for the formation of $\mathrm{C}_{2} \mathrm{H}_{5} \mathrm{OCH}_{3}$ and its consumption pathways (Sub 3) were originated from an existing model [43]. Thermochemical and transport properties were originated from previous models $[3,35,41,43]$, which generally agree well with available measured values provided by the NIST database [44].

\section{Table 1}

The added or updated reactions for DEC pyrolysis and combustion in this work. Rate coefficients are given as $k=\mathrm{AT}^{\mathrm{n}} \exp \left(-\mathrm{E}_{\mathrm{a}} / \mathrm{RT}\right)$. Units are $\mathrm{s}^{-1}, \mathrm{~cm}^{3}$ and cal/mol.

\begin{tabular}{lllllll}
\hline No. & Reactions & Pressure & $\mathrm{A}$ & $\mathrm{n}$ & $\mathrm{E}_{\mathrm{a}}$ & Ref. \\
\hline $\mathrm{R} 1$ & $\mathrm{DEC}=\mathrm{CCOC} * \mathrm{OOH}+\mathrm{C}_{2} \mathrm{H}_{4}$ & $0.01 \mathrm{~atm}$ & $3.13 \times 10^{27}$ & -4.56 & $5.33 \times 10^{4}$ & This work \\
& & $0.1 \mathrm{~atm}$ & $2.68 \times 10^{21}$ & -2.64 & $5.51 \times 10^{4}$ & \\
& $1 \mathrm{~atm}$ & $9.78 \times 10^{15}$ & -0.94 & $4.95 \times 10^{4}$ & \\
& $10 \mathrm{~atm}$ & $7.92 \times 10^{13}$ & -0.28 & $4.88 \times 10^{4}$ & \\
& $100 \mathrm{~atm}$ & $3.26 \times 10^{9}$ & 1.05 & $4.70 \times 10^{4}$ & \\
& & $0.01 \mathrm{~atm}$ & $1.54 \times 10^{39}$ & -8.15 & $7.05 \times 10^{4}$ & This work \\
& & $0.1 \mathrm{~atm}$ & $2.46 \times 10^{29}$ & -5.03 & $6.75 \times 10^{4}$ & \\
& $\mathrm{DEC}=\mathrm{C}_{2} \mathrm{H}_{5} \mathrm{OH}+\mathrm{CO}_{2}+\mathrm{C}_{2} \mathrm{H}_{4}$ & $1 \mathrm{~atm}$ & $7.31 \times 10^{20}$ & -2.36 & $6.45 \times 10^{4}$ & \\
& $10 \mathrm{~atm}$ & $1.01 \times 10^{17}$ & -1.14 & $6.33 \times 10^{4}$ & \\
& $100 \mathrm{~atm}$ & $5.41 \times 10^{10}$ & 0.76 & $6.07 \times 10^{4}$ & \\
& & $0.01 \mathrm{~atm}$ & $1.58 \times 10^{51}$ & -11.50 & $8.18 \times 10^{4}$ & This work \\
& $\mathrm{DEC}=\mathrm{C}_{2} \mathrm{H}_{5} \mathrm{OC}_{2} \mathrm{H}_{5}+\mathrm{CO}_{2}$ & $0.1 \mathrm{~atm}$ & $3.94 \times 10^{39}$ & -7.78 & $7.83 \times 10^{4}$ & \\
& $1 \mathrm{~atm}$ & $3.58 \times 10^{29}$ & -4.63 & $7.48 \times 10^{4}$ &
\end{tabular}


$\mathrm{R} 4 \quad \mathrm{CCOC} * \mathrm{OOH}=\mathrm{C}_{2} \mathrm{H}_{5} \mathrm{OH}+\mathrm{CO}_{2}$

R5 $\mathrm{CCOC}^{*} \mathrm{OOH}=\mathrm{C}_{2} \mathrm{H}_{4}+\mathrm{HOC}^{*} \mathrm{OOH}$

R6 $\quad \mathrm{HOC}^{*} \mathrm{OOH}=\mathrm{CO}_{2}+\mathrm{H}_{2} \mathrm{O}$

Sub 1 consumption pathways of $\mathrm{C}_{2} \mathrm{H}_{5} \mathrm{OC}_{2} \mathrm{H}_{5}$

$\mathrm{R} 7 \mathrm{DEC}+\mathrm{H}=\mathrm{CJCOC} * \mathrm{OOCC}+\mathrm{H}_{2}$

$\mathrm{R} 8 \mathrm{DEC}+\mathrm{H}=\mathrm{CCJOC} * \mathrm{OOCC}+\mathrm{H}_{2}$

Sub $2 \mathrm{CH}_{3} \mathrm{COOH}$ reactions

R9 $\mathrm{CH}_{3} \mathrm{CHO}+\mathrm{OH}=\mathrm{CH}_{3} \mathrm{COOH}+\mathrm{H}$

$\mathrm{R} 10 \quad \mathrm{CH}_{3} \mathrm{O}+\mathrm{C}_{2} \mathrm{H}_{5}=\mathrm{C}_{2} \mathrm{H}_{5} \mathrm{OCH}_{3}$

Sub 3 consumption pathways of $\mathrm{C}_{2} \mathrm{H}_{5} \mathrm{OCH}_{3}$

100 atm $\quad 4.76 \times 10^{17} \quad-0.98 \quad 7.03 \times 10^{4}$

$0.01 \mathrm{~atm} \quad 2.04 \times 10^{54} \quad-12.91 \quad 5.24 \times 10^{4}$

$0.1 \mathrm{~atm} \quad 2.77 \times 10^{47} \quad-10.56 \quad 5.12 \times 10^{4}$

$1 \mathrm{~atm} \quad 1.55 \times 10^{39} \quad-7.87 \quad 4.90 \times 10^{4}$

$10 \mathrm{~atm}$

$1.12 \times 10^{31}$

$-5.29$

$4.64 \times 10^{4}$

$100 \mathrm{~atm}$

$2.98 \times 10^{23}$

$-2.96$

$4.35 \times 10^{4}$

$0.01 \mathrm{~atm}$

$9.87 \times 10^{57}$

$-14.64$

$5.93 \times 10^{4}$

$0.1 \mathrm{~atm}$

$3.93 \times 10^{52}-12.59$

$5.94 \times 10^{4}$

$1 \mathrm{~atm}$

$1.58 \times 10^{44}$

$-9.75$

$5.77 \times 10^{4}$

10 atm

$2.56 \times 10^{34}$

$-6.61$

$5.50 \times 10^{4}$

$100 \mathrm{~atm}$

$5.91 \times 10^{24}-3.61$

$5.14 \times 10^{4}$

$0.01 \mathrm{~atm}$

$3.88 \times 10^{36}$

$-7.98$

$4.52 \times 10^{4}$

$0.1 \mathrm{~atm}$

$2.44 \times 10^{37}$

$-7.89$

$4.71 \times 10^{4}$

$1 \mathrm{~atm}$

$6.28 \times 10^{36}$

$-7.40$

$4.85 \times 10^{4}$

$10 \mathrm{~atm}$

$1.73 \times 10^{35}-6.66$

$4.95 \times 10^{4}$

$100 \mathrm{~atm}$

$3.73 \times 10^{30}-5.07$

$4.88 \times 10^{4}$

$\begin{array}{lll}1.15 \times 10^{11} & 1.21 & 9.90 \times 10^{3}\end{array}$

$3.17 \times 10^{10} \quad 1.23 \quad 6.08 \times 10^{3}$

$5.00 \times 10^{11} \quad 0.00 \quad 0.00 \quad$ Estimated

$1.00 \times 10^{13} \quad 0.00 \quad 0.00$

Estimated [43]

Notes: $\mathrm{CCOC}^{*} \mathrm{OOH}, \mathrm{C}_{2} \mathrm{H}_{5} \mathrm{OC}(=\mathrm{O}) \mathrm{OH} ; \mathrm{HOC}^{*} \mathrm{OOH}, \mathrm{HOC}(=\mathrm{O}) \mathrm{OH} ; \mathrm{CJCOC}^{*} \mathrm{OOCC}, \dot{\mathrm{C}} \mathrm{H}_{2} \mathrm{CH}_{2} \mathrm{OC}(=\mathrm{O}) \mathrm{OC}_{2} \mathrm{H}_{5}$; CCJOC $*$ OOCC, $\mathrm{CH}_{3} \dot{\mathrm{C}} \mathrm{HOC}(=\mathrm{O}) \mathrm{OC}_{2} \mathrm{H}_{5}$

All simulations in the present study were accomplished with the Chemkin Pro [45] program. The PLUG code was employed to reproduce the pyrolysis experiments. As proven in [6], the basic assumption for the plug-flow reactor of negligible axial diffusion relative to convection is fairly reasonable in the present experimental configuration. The measured temperature profiles corresponding to each $T_{\max }$ was taken as input under all experimental conditions to calculate species mole fraction profiles along the flow reactor. Since the measurements were performed only at the outlet of the flow tube, the simulated values at this position were compared with experimental results. The PREMIX module was adopted for the simulation of the premixed flame structure. The measured temperature profile was taken as input, and the mixture-averaged transport and the thermal diffusion were considered in the simulation. Up to 250 grids were used to obtain the converged, grid-independent solution with gradient and curvature tolerances (GRAD and CURV) set as 0.1 and 0.05 , respectively. 


\section{Results and discussion}

Model performances under high temperature conditions were tested with the species mole fraction profiles measured in this work as well as the laminar burning velocities reported in [4]. Particular attention was paid to key intermediates and reactions to interpret the combustion characteristics of DEC, which was also compared to those of DMC, a simpler homologue of DEC, under similar conditions. Extending comparisons were made between DEC and other specific oxygenated fuels sharing the same structural features with DEC.

\subsection{DEC pyrolysis in a flow reactor}

Mole fractions for DEC and the major pyrolysis products $\left(\mathrm{C}_{2} \mathrm{H}_{4}, \mathrm{C}_{2} \mathrm{H}_{5} \mathrm{OH}, \mathrm{CO}_{2}\right)$ were determined in current experiments, as the symbols with error bars shown in Fig. 3. The measurements at the outlet of the flow tube were plotted against $T_{\max }$ of corresponding temperature profiles. Simulations with both the modified model and the original version [3] were shown for comparisons. Weak signals for acetaldehyde $\left(\mathrm{CH}_{3} \mathrm{CHO}\right)$ and $\mathrm{C}_{2} \mathrm{H}_{5} \mathrm{OC}_{2} \mathrm{H}_{5}$ were detected at relatively high temperatures, which however could not be reliably quantified due to the low signal-noise ratio. According to Fig. 3, improved predictions were achieved with the modified model under all three different pressures. Rate of production (ROP) analysis was performed on DEC and the products $\left(\mathrm{C}_{2} \mathrm{H}_{4}, \mathrm{C}_{2} \mathrm{H}_{5} \mathrm{OH}, \mathrm{CO}_{2}\right)$, and the results suggested that the fuel was almost exclusively consumed through the six-membered elimination (R1), which also contributed to more than $99 \%$ of $\mathrm{C}_{2} \mathrm{H}_{4}$ formation under all investigated conditions. And the subsequent decomposition of $\mathrm{C}_{2} \mathrm{H}_{5} \mathrm{OC}(=\mathrm{O}) \mathrm{H}$ (R4) was found to be the sole reaction accounting for the formation of $\mathrm{C}_{2} \mathrm{H}_{5} \mathrm{OH}$ and $\mathrm{CO}_{2}$.

The dominance of the two-step decomposition in DEC unimolecular decomposition has already been addressed in previous studies $[24,25]$. In the present work, the pressure and temperature dependent rate coefficients for DEC dissociations were theoretically determined for the first time. The computed rate coefficients for R1 and R4 are plotted in Fig. 4 and those used in the original model [3] are also shown for comparison. Our calculations suggest non-negligible fall-off effects for both reactions over the temperature range covered by our pyrolysis experiment (700-1200 K). The rate coefficient of R1 at $0.01 \mathrm{~atm}$ is about half of the high pressure limit (HPL). And the fall-off behavior of R4 is even more remarkable, as shown in Fig. 4(b). As indicated by Fig. 3, the model performance at low pressures is largely improved by including the pressure-dependence. The rate 
coefficient for R1 used in the model by Nakamura et al. [3] was obtained by extrapolating an experimental measurement [26], which approaches our calculated HPL above $1600 \mathrm{~K}$, though a three-fold difference can be observed over the temperature range of the measurement (950-1100 K) [26]. Such a discrepancy is not surprising since uncertainties of a factor of 2 in the A factor and 500 $\mathrm{K}$ in the activation energy were claimed in the previous measurement [26]. Whereas for $\mathrm{R} 4$, the decomposition of $\mathrm{C}_{2} \mathrm{H}_{5} \mathrm{OC}(=\mathrm{O}) \mathrm{OH}$ into $\mathrm{C}_{2} \mathrm{H}_{5} \mathrm{OH}$ and $\mathrm{CO}_{2}$, the rate coefficient adopted in the original model [3] was a rough estimation from a barrier height computed at the level of MP2/6-311++G(2d,p)//MP2/6-31G(d) [24], which is significantly over-estimated compared with the $\mathrm{RRKM} /$ master equation results. This reaction proceeds much faster than $\mathrm{R} 1$, making $\mathrm{R} 1$ the rate-limiting step in the DEC decomposition process. The simultaneous formation of the three products as shown in Fig. 3 also indicates that the reactive $\mathrm{C}_{2} \mathrm{H}_{5} \mathrm{OC}(=\mathrm{O}) \mathrm{OH}$ promptly decomposes.

Similar pyrolysis experiments for DMC have been accomplished with the same apparatus in our previous study and the measured fuel mole fraction profiles for DMC [6] and DEC are compared in Fig. 5. It can be found that the consumption and depletion of DMC proceeds at much higher temperatures. The principal reaction leading to about $50 \%$ of DMC consumption was a four-membered $\mathrm{CO}_{2}$ elimination $\left(\mathrm{DMC}=\mathrm{CH}_{3} \mathrm{OCH}_{3}+\mathrm{CO}_{2}\right)$, as pointed out in [6]. A similar reaction (R3, DEC $=\mathrm{C}_{2} \mathrm{H}_{5} \mathrm{OC}_{2} \mathrm{H}_{5}+\mathrm{CO}_{2}$ ) was also considered in the DEC unimolecular system, but found far less competitive compared to R1. The presence of hydrogen atoms on the $\beta$-sites (see Scheme1) in DEC allows the occurrence of the energy-favored six-centered hydrogen transfer (R1) which cannot occur in a DMC molecule, and such a structural difference results in the less thermal stability of DEC. Apart from the important intra-molecular elimination, bimolecular reactions including hydrogen abstractions by $\mathrm{H}$ and $\mathrm{CH}_{3}$, also contribute to the consumption of DMC under pyrolysis conditions [6], which are however negligible in the current case of DEC.

Since the consumption process of DEC is accomplished in a relatively low temperature range in which R1 is exclusively dominant and radicals are of minimal levels, the measured species pool of DEC pyrolysis is quite "clean". Experimental measurements were stopped when over $90 \%$ fuel was consumed because we focused on DEC decomposition channels, while Fig. 6 presents the simulated results in a wider temperature range under the pressure of 780 Torr. It can be seen that the decomposition of $\mathrm{C}_{2} \mathrm{H}_{5} \mathrm{OH}$ enriches the species pool after the depletion of DEC. A second stage of 
rise shows in the mole fraction of $\mathrm{C}_{2} \mathrm{H}_{4}$, which is mainly attributed to the $\mathrm{H}_{2} \mathrm{O}$ elimination of

$\mathrm{C}_{2} \mathrm{H}_{5} \mathrm{OH}$ according to the ROP-analyzed results. $\mathrm{CH}_{3} \mathrm{CHO}$ is formed from the $\beta$-scission of the $\mathrm{CH}_{3} \dot{\mathrm{C}} \mathrm{HOH}$ radical following the hydrogen abstractions from the secondary carbon atoms, the dominant channel of $\mathrm{C}_{2} \mathrm{H}_{5} \mathrm{OH}$ consumption. The production of $\mathrm{CO}$, a conventional major product of oxygenates pyrolysis, mainly results from the decomposition of the acetyl radial $\left(\mathrm{CH}_{3} \dot{\mathrm{CO}}\right)$ and far lags behind the production of $\mathrm{CO}_{2}$. At higher temperatures, the consumption of $\mathrm{C}_{2} \mathrm{H}_{4}$ accounts for the formation of $\mathrm{C}_{2} \mathrm{H}_{2}$.

\subsection{Fuel consumption pathways and the species pool in the premixed flame}

The flame structure measurements of high fidelity can extensively test the DEC model performance under combustion conditions. The comparisons between experimental and modeling results are illustrated in Fig. 7 and Fig. 8. Data points within $1 \mathrm{~mm}$ from the burner surface are shown in light colors considering possible higher uncertainties caused by the perturbation from the sampling nozzle in this region [46]. For the major species $\left(\mathrm{O}_{2}, \mathrm{H}_{2} \mathrm{O}, \mathrm{CO}, \mathrm{CO}_{2}, \mathrm{Ar}\right.$, DEC) shown in Fig. 7, the measurements can be well reproduced by the model within experimental uncertainties. $\mathrm{CO}_{2}$ and $\mathrm{CO}$ are produced at a similar pace and this was also captured in DMC premixed flames [6]. Intermediates measured in the DEC flame include $\mathrm{C}_{1}-\mathrm{C}_{4}$ hydrocarbon and oxygenated species, among which the intermediates related to fuel chemistry are presented in Fig. 8. The kinetic model can satisfactorily predict the measurements except for the slightly over-predictions of propane $\left(\mathrm{C}_{3} \mathrm{H}_{8}\right)$ and propene $\left(\mathrm{C}_{3} \mathrm{H}_{6}\right)$ concentrations. To pursue the intermediates formation along the fuel consumption pathways, ROP analyses were performed for specific species in the entire flame range. Fuel related reaction pathways were summarized based on the distance integrals of ROP coefficients, as demonstrated in Fig. 9.

The consumption of DEC in the flame conditions is quite different from that in the pyrolysis conditions, as indicated by the diversity of the species pool and the relatively complicated reaction network. As discussed above, the DEC consumption is exclusively controlled by the six-membered elimination $\left[\mathrm{DEC}=\mathrm{C}_{2} \mathrm{H}_{5} \mathrm{OC}(=\mathrm{O}) \mathrm{OH}+\mathrm{C}_{2} \mathrm{H}_{4}\right]$ under the pyrolysis conditions, however, it only contributes to less than one-third of fuel consumption in the studied DEC flames, as shown in Fig. 9. Instead, the fuel decomposition is dominated by hydrogen abstractions. Due to the different strength of different $\mathrm{C}-\mathrm{H}$ bonds, approximately $50 \%$ of the fuel is consumed through the hydrogen 
abstractions from the secondary carbon atoms while those from the primary carbon atoms contribute

about $22 \%$ of the fuel consumption. Two different fuel radicals, $\mathrm{CH}_{3} \dot{\mathrm{C}} \mathrm{HOC}(=\mathrm{O}) \mathrm{OC}_{2} \mathrm{H}_{5}$ and $\dot{\mathrm{C}} \mathrm{H}_{2} \mathrm{CH}_{2} \mathrm{OC}(=\mathrm{O}) \mathrm{OC}_{2} \mathrm{H}_{5}$, are formed, which then easily break down and yield smaller species. The three major products $\left(\mathrm{CO}_{2}, \mathrm{C}_{2} \mathrm{H}_{4}\right.$ and $\left.\mathrm{C}_{2} \mathrm{H}_{5} \mathrm{OH}\right)$ measured in the pyrolysis experiments are also of high concentrations in the premixed flame, but the formation channels for these species might be different from those under the pyrolysis conditions. $\mathrm{C}_{2} \mathrm{H}_{5} \mathrm{OH}$ is exclusively produced from the decomposition of $\mathrm{C}_{2} \mathrm{H}_{5} \mathrm{OC}(=\mathrm{O}) \mathrm{OH}$, just the same as the case of pyrolysis, whereas more reactions are involved in the formation of $\mathrm{CO}_{2}$ and $\mathrm{C}_{2} \mathrm{H}_{4}$, according to the $\mathrm{ROP}$ analysis along the distance from the burner exhibited in Fig. 10. The steep rise of $\mathrm{CO}_{2}$ mole fraction near the burner is attributed to three fuel-related reactions, i.e. the repeatedly mentioned molecular decomposition process (R1 and R4), and the fissions of two radicals $\mathrm{C}_{2} \mathrm{H}_{5} \mathrm{OC}(=\mathrm{O})$ and $\mathrm{C}_{2} \mathrm{H}_{5} \mathrm{OC}(=\mathrm{O}) \dot{\mathrm{O}}$ which are produced after a few $\beta$-scission steps following the abstractions from the secondary and the primary carbon atoms, respectively. Among these reactions, the decomposition of $\mathrm{C}_{2} \mathrm{H}_{5} \mathrm{OC}(=\mathrm{O})$ contributes the most due to the predominance of hydrogen abstractions from the secondary carbon atoms in the fuel consumption. More generally, it can be seen that each of the three fuel consumption pathways yields $\mathrm{CO}_{2}$, as underlined in Fig. 9, which gives an explanation to the early formation of $\mathrm{CO}_{2}$ as mentioned above. With the fuel depleted, the reaction $\left(\mathrm{CO}+\mathrm{OH}=\mathrm{CO}_{2}+\mathrm{H}\right)$ becomes dominant in the region further from the burner [see Fig. 10 (a)], which is usually the only reaction accounting for $\mathrm{CO}_{2}$ formation in conventional hydrocarbon flames. $\mathrm{C}_{2} \mathrm{H}_{4}$ is the most abundant intermediate in the DEC premixed flame, as shown in Fig. 8. The six-centered elimination (R1) governs $\mathrm{C}_{2} \mathrm{H}_{4}$ formation in a narrow region near the burner while the reaction $\left[\mathrm{C}_{2} \mathrm{H}_{4}+\mathrm{H}(+\mathrm{M})=\mathrm{C}_{2} \mathrm{H}_{5}(+\mathrm{M})\right]$ becomes a comparable $\mathrm{C}_{2} \mathrm{H}_{4}$ contributor further away from the burner. Coming after these two reactions is the $\beta$-scission of the primary fuel radical $\dot{\mathrm{CH}}_{2} \mathrm{CH}_{2} \mathrm{OC}(=\mathrm{O}) \mathrm{OC}_{2} \mathrm{H}_{5}$, and the $\mathrm{H}_{2} \mathrm{O}$ elimination of $\mathrm{C}_{2} \mathrm{H}_{5} \mathrm{OH}$ begins to play a role downstream the peak position of $\mathrm{C}_{2} \mathrm{H}_{4}$ mole fractions.

$\mathrm{CH}_{3} \mathrm{CHO}$ is the intermediate with the second highest peak mole fraction of over $20000 \mathrm{ppm}$, approximately $70 \%$ of which is formed from the $\beta$-scission of the fuel radical $\mathrm{CH}_{3} \dot{\mathrm{C}} \mathrm{HOC}(=\mathrm{O}) \mathrm{OC}_{2} \mathrm{H}_{5}$ after the prevailing hydrogen abstractions from the secondary carbon atoms, according to the ROP analysis. Carbon atoms are fixed in the carbon-oxygen double bonds $(\mathrm{C}=\mathrm{O})$ with the formation of $\mathrm{CH}_{3} \mathrm{CHO}$, leading to a reduced carbon flux to $\mathrm{C}_{2} \mathrm{H}_{4}$. The stable $(\mathrm{C}=\mathrm{O})$ structure is preserved in 
several oxygenated intermediates produced mainly from the consumption of $\mathrm{CH}_{3} \mathrm{CHO}$, such as ketene $\left(\mathrm{CH}_{2} \mathrm{CO}\right)$ and $\mathrm{CH}_{3} \mathrm{COOH}$. While ethenol $\left(\mathrm{C}_{2} \mathrm{H}_{3} \mathrm{OH}\right)$, an isomer of $\mathrm{CH}_{3} \mathrm{CHO}$ without $(\mathrm{C}=\mathrm{O})$, predominantly comes from the $\mathrm{C}_{2} \mathrm{H}_{5} \mathrm{OH}$ consumption, as seen in Fig. 9. Ethyl $\left(\mathrm{C}_{2} \mathrm{H}_{5}\right)$ is another noticeable intermediate because it is yielded from the dissociation of a fuel related radical, $\mathrm{C}_{2} \mathrm{H}_{5} \mathrm{OC}(=\mathrm{O})$, and more importantly, because it leads to the formation of most measured hydrocarbons. As shown in Fig. 9, three channels are involved in the consumption of $\mathrm{C}_{2} \mathrm{H}_{5}$, respectively leading to the production of $\mathrm{CH}_{3}, \mathrm{C}_{2} \mathrm{H}_{4}$ and propane $\left(\mathrm{C}_{3} \mathrm{H}_{8}\right)$. According to the ROP-analyzed results, $\mathrm{CH}_{3}$ can be oxidized to $\mathrm{CH}_{2} \mathrm{O}$ while $\mathrm{C}_{2} \mathrm{H}_{4}$ and $\mathrm{C}_{3} \mathrm{H}_{8}$ are mainly consumed through dehydrogenation processes, producing unsaturated $\mathrm{C}_{2}$ and $\mathrm{C}_{3}$ intermediates accordingly. Therefore, mole fractions for hydrocarbon species of higher degrees of unsaturation peak more downstream, which can be seen in Fig. 8(b)-(d).

Compared to those in the DMC flames [6], $\mathrm{C}_{2}-\mathrm{C}_{4}$ hydrocarbon intermediates are of much higher concentrations in the DEC flame because of the direct yields of $\mathrm{C}_{2} \mathrm{H}_{4}$ and $\mathrm{C}_{2} \mathrm{H}_{5}$ from the fuel consumption. While in DMC flames, due to the absence of C-C bonds in the fuel molecule, intermediates containing $\mathrm{C}-\mathrm{C}$ bonds cannot be directly produced from the fuel consumption. Corresponding aldehydes, $\mathrm{CH}_{2} \mathrm{O}$ and $\mathrm{CH}_{3} \mathrm{CHO}$, are of abundance respectively in flames of DMC and $\mathrm{DEC}$, as they can be easily formed from the $\beta$-scissions in $\mathrm{C}-\mathrm{O}$ bonds $[\mathrm{C}(=\mathrm{O})-\mathrm{O}]$ of fuel radicals following hydrogen abstractions, the predominant fuel consumption channels in flame conditions.

As a further validation, the kinetic model was also tested with the laminar burning velocities reported in [4], as shown in Fig. 11. The modified model predicts well the measurements and has comparable performance with the original model. This can be expected because as pointed out in [4], the propagation of the DEC/air flame is exclusively governed by reactions of small molecules, which have not been updated in this work.

\subsection{Structural features $v s$. combustion characteristics}

Improving energy utilization while minimizing pollutants of all types is demanded in the development of advanced combustion modes. In pursuit of such targets, the concept of fuel design, such as fuel additives and fuel blending, has been proposed [47]. Various oxygenated compounds have been examined in search of suitable ones as fuel additives or alternatives with proper physical-chemical properties. With the accumulated kinetic knowledge of various oxygenated fuels, 
it can be expected to find some general connections between structural features and combustion characteristics.

As demonstrated in Scheme 2, several oxygenated moieties are imbedded in the molecular structure of DEC, which are also present in other oxygenates of different categories. Combustion characteristics shared by fuels with the same structural features will be discussed in this section.

Symmetrical $\left[\mathrm{CH}_{3} \mathrm{CH}_{2} \mathrm{OC}(=\mathrm{O})-\right]$ groups can be found in DEC and such a moiety is usually bonded to different alkyls in ethyl esters. This structure allows a six-centered hydrogen transfer from the $\beta$-carbon to the carbonyl oxygen, producing $\mathrm{C}_{2} \mathrm{H}_{4}$ and corresponding acids. Being of relatively low energy barriers ( less than $50 \mathrm{kcal} / \mathrm{mol}$ [48]), these intermolecular eliminations are the dominant fuel consumption channels under pyrolysis conditions for both DEC and ethyl esters [49]. These reactions also account for the higher reactivity of ethyl esters, relative to corresponding methyl esters of the same alkanoic acid [50]. The $\left[\mathrm{CH}_{3} \mathrm{CH}_{2} \mathrm{OC}(=\mathrm{O})-\right]$ group, as a radical $\left[\mathrm{C}_{2} \mathrm{H}_{5} \mathrm{OC}(=\mathrm{O})\right]$ itself, is easily formed in flames of both DEC and ethyl esters. More generally, the fate of the $\mathrm{ROC}(=\mathrm{O})$ radical $\left(\mathrm{R}=\mathrm{CH}_{3}, \mathrm{C}_{2} \mathrm{H}_{5}\right)$ has always been related to the "efficiency of oxygen atom usage" $[3,51,52]$. The competing channels of $\mathrm{CH}_{3} \mathrm{OC}(=\mathrm{O})$ decomposition, respectively leading to $\mathrm{CH}_{3}+\mathrm{CO}_{2}$ and $\mathrm{CH}_{3} \mathrm{O}+\mathrm{CO}$, have been investigated in several theoretical studies which reported energy barriers [51, 53-56] at different levels of theory, and rate coefficients were calculated in a few of them $[51,55,56]$, as summarized in Table S2. For $\mathrm{C}_{2} \mathrm{H}_{5} \mathrm{OC}(=\mathrm{O})$, few calculations are available, so Nakamura et al. [3] adopted the calculations by Klippenstein for $\mathrm{CH}_{3} \mathrm{OC}(=\mathrm{O})$ by analogy, which was also employed in the present model. The branching ratios between the $\mathrm{CO}_{2}$ and $\mathrm{CO}$ channels from different origins $[3,51,55,56]$ are presented in Fig. S5. The results reported in recent years $[3,56]$ facilitated better model predictions for $\mathrm{CO}_{2}$ mole fractions [3, 6] and both works consistently suggested that the channel leading to $\mathrm{CO}$ takes a negligible branching ratio. In this regard, the two oxygen atoms in $\mathrm{ROC}(=\mathrm{O})$ remain bonded to the single carbon atom instead of effectively preventing other carbon atoms from forming soot.

The common moiety shared by the carbonates is the [-OC $(=\mathrm{O}) \mathrm{O}-]$ group. Two oxygen atoms are bonded to the $[-\mathrm{C}(=\mathrm{O})-]$ structure, resulting in the easy formation of $\mathrm{CO}_{2}$ under both pyrolysis and combustion conditions. By taking DMC [6] and DEC as examples, it could be found that $\mathrm{CO}_{2}$ is 
released within a few steps along all fuel consumption pathways, either unimolecular dissociations or hydrogen abstractions. The principal unimolecular decomposition channels for DMC and DEC are respectively a four-membered elimination $\left(\mathrm{DMC} \rightarrow \mathrm{CH}_{3} \mathrm{OCH}_{3}+\mathrm{CO}_{2}\right.$ ) and a two-step $\mathrm{H}$ transfer $\left(\mathrm{DEC} \rightarrow \mathrm{C}_{2} \mathrm{H}_{5} \mathrm{OC}(=\mathrm{O}) \mathrm{OH}+\mathrm{C}_{2} \mathrm{H}_{4} \rightarrow \mathrm{C}_{2} \mathrm{H}_{5} \mathrm{OH}+\mathrm{CO}_{2}+\mathrm{C}_{2} \mathrm{H}_{4}\right)$, both directly emitting $\mathrm{CO}_{2}$. And two types of fuel related radicals, $\operatorname{ROC}(=\mathrm{O}) \dot{\mathrm{O}}$ and $\mathrm{ROC}(=\mathrm{O})$, are both exclusively consumed by the energy-favored $\beta$-scissions, yielding $\mathrm{CO}_{2}$. Therefore two oxygen atoms in the [-OC(=O)O-] group are directly fixed in a $\mathrm{CO}_{2}$ molecule in fuel decompositions instead of oxidizing hydrocarbons in the species pool. In this regard, DME $\left(\mathrm{CH}_{3} \mathrm{OCH}_{3}\right)$ and $\mathrm{DEE}\left(\mathrm{C}_{2} \mathrm{H}_{5} \mathrm{OC}_{2} \mathrm{H}_{5}\right)$, molecules obtained by subtracting a $\mathrm{CO}_{2}$ respectively from DMC and DEC, can be expected of comparable soot reducing potentials with the carbonates which have much higher oxygen contents. But for the practical application, the carbonates show much better physical properties than corresponding ethers as fuel additives, such as boiling point, vapor pressure, viscosity and solubility in diesel.

The $\left(\mathrm{CH}_{3} \mathrm{CH}_{2} \mathrm{O}-\right)$ structures, on both ends of a DEC molecule, is ubiquitous in numerous oxygenated fuels, such as diethyl ether $\left(\mathrm{CH}_{3} \mathrm{CH}_{2} \mathrm{OCH}_{2} \mathrm{CH}_{3}, \mathrm{DEE}\right)$ and the above-mentioned ethyl esters. Two types of hydrogen atoms in this moiety are available for abstractions which govern the fuel consumption under flame conditions. The branching ratio between the hydrogen abstractions from different sites could be related to the strength of the two different $\mathrm{C}-\mathrm{H}$ bonds. Recommended BDE values [57] for primary, secondary and tertiary $\mathrm{C}-\mathrm{H}$ bonds in typical $\mathrm{C}_{3}-\mathrm{C}_{5}$ hydrocarbons are in the ranges of $100.2-100.9 \mathrm{kcal} / \mathrm{mol}, 98.1-99.2 \mathrm{kcal} / \mathrm{mol}$ and $94.7-95.7 \mathrm{kcal} / \mathrm{mol}$, respectively. And the calculated BDEs at the $\mathrm{G} 4$ level of theory for the $\mathrm{C}-\mathrm{H}$ bonds in $\left(\mathrm{CH}_{3} \mathrm{CH}_{2} \mathrm{O}-\right)$ moieties of DEC, $\mathrm{C}_{3}-\mathrm{C}_{5}$ ethyl esters and DEE are listed in Table S3. The secondary C-H bonds (92.7-96.6 $\mathrm{kcal} / \mathrm{mol})$ are weakened by the neighboring oxygen atoms in $\left(\mathrm{CH}_{3} \mathrm{CH}_{2} \mathrm{O}-\right)$, with BDEs equivalent with or lower than those of conventional tertiary $\mathrm{C}-\mathrm{H}$ bonds, while the primary $\mathrm{C}-\mathrm{H}$ bonds (100.1-101.1 kcal/mol) are negligibly affected. The hydrogen abstractions from the secondary carbon atoms and the primary carbon atoms have a relative contribution of 48:22 and 76:19 to the fuel consumption in the current DEC flame and a fuel-rich DEE flame reported in [35]. The overwhelming significance of the hydrogen abstractions from the secondary carbon atoms gives rise 
to the remarkable levels of $\mathrm{CH}_{3} \mathrm{CHO}$ observed in the DEC and DEE [35] flames, which is easily formed from $\beta$-scissions of corresponding fuel radicals.

\section{Conclusion}

High temperature combustion kinetics of DEC was investigated in this work, with emphasis on probing quantitative speciation information under pyrolysis and combustion conditions. Mole fraction variations during DEC pyrolysis under different pressures were measured with a GC system while the chemical structure of a fuel-rich DEC flame was obtained using photoionization mass spectrometry (PI-MBMS). Improvements in the kinetic model were achieved mainly by updating DEC unimolecular decompositions with theoretically determined rate coefficients and by adding sub-mechanisms for several measured intermediates. A six-membered elimination with relatively low energy barrier was found to exclusively govern the fuel consumption in pyrolysis conditions and also play a role in the premixed flame. An unusual early formation of $\mathrm{CO}_{2}$ was observed under the premixed flame conditions because of the rapid decomposition of $\mathrm{C}_{2} \mathrm{H}_{5} \mathrm{OC}(=\mathrm{O}) \mathrm{OH}$ and the $\beta$-scission of $\mathrm{C}_{2} \mathrm{H}_{5} \mathrm{OC}(=\mathrm{O})$ and $\mathrm{C}_{2} \mathrm{H}_{5} \mathrm{OC}(=\mathrm{O}) \mathrm{O}$ radicals. And several intermediates, such as $\mathrm{C}_{2} \mathrm{H}_{4}, \mathrm{CH}_{3} \mathrm{CHO}, \mathrm{C}_{2} \mathrm{H}_{5} \mathrm{OH}$ and $\mathrm{C}_{2} \mathrm{H}_{5}$, were observed of significant levels, because their formation was closely related to the major fuel consumption pathways. Connections between structural features and combustion characteristics were highlighted in this work by comparing DEC with different fuels sharing the same oxygenated moieties. The $\left[\mathrm{CH}_{3} \mathrm{CH}_{2} \mathrm{OC}(=\mathrm{O})-\right]$ group existing in both ethyl esters and DEC allows six-membered eliminations with relatively low energy barriers. And the preference of $\mathrm{CO}_{2}$ yield from $\mathrm{ROC}(=\mathrm{O})$ radicals has been verified with recent theoretical calculations and the early $\mathrm{CO}_{2}$ formation in flames of esters and carbonates. The [-OC( $=\mathrm{O}) \mathrm{O}-]$ functional group in carbonates further facilitates the $\mathrm{CO}_{2}$ production as $\mathrm{CO}_{2}$ is released in initial steps of all consumption pathways of DMC and DEC. The oxygen atom in $\left(\mathrm{CH}_{3} \mathrm{CH}_{2} \mathrm{O}-\right)$ weakens the neighboring $\mathrm{C}-\mathrm{H}$ bonds, making the hydrogen atoms easier to be abstracted. The subsequent $\beta$-scissions of the resulting radicals explain the abundance of $\mathrm{CH}_{3} \mathrm{CHO}$ in DEC and DEE flames.

\section{Acknowledgment}

This work is supported by the National Natural Science Foundation of China (No. 91541113, 91541112) and Beijing Natural Science Foundation (No. 3162015). NH is supported by the U.S. 
Department of Energy (USDOE), Office of Basic Energy Sciences (BES) under Grant No.

DE-AC04-94-AL85000. The experiments were profited from the expert technical assistance of Paul Fugazzi. The authors are grateful to Professors Fei Qi, Yuyang Li and Jiuzhong Yang for their helps in the pyrolysis experiments. The Advanced Light Source is supported by the Director, Office of Science, BES, USDOE under Contract No. DE-AC02-05CH11231. Sandia is a multi-mission laboratory operated by Sandia Corporation, a Lockheed Martin Company, for the National Nuclear Security Administration under contract DE-AC04-94-AL85000.

\section{References}

[1] K. Kohse - Höinghaus, P. Oßwald, T.A. Cool, T. Kasper, N. Hansen, F. Qi, C.K. Westbrook, P.R. Westmoreland, Biofuel combustion chemistry: from ethanol to biodiesel, Angew. Chem. Int. Edit 49 (2010) $3572-3597$.

[2] C.K. Westbrook, W.J. Pitz, H.J. Curran, Chemical kinetic modeling study of the effects of oxygenated hydrocarbons on soot emissions from diesel engines, J. Phys. Chem. A 110 (2006) 6912-6922.

[3] H. Nakamura, H.J. Curran, A.P. Córdoba, W.J. Pitz, P. Dagaut, C. Togbé, S.M. Sarathy, M. Mehl, J.R. Agudelo, F. Bustamante, An experimental and modeling study of diethyl carbonate oxidation, Combust. Flame 162 (2015) 1395-1405.

[4] R. Shahla, C. Togbé, S. Thion, R. Timothée, M. Lailliau, F. Halter, C. Chauveau, G. Dayma, P. Dagaut, Burning velocities and jet-stirred reactor oxidation of diethyl carbonate, Proc. Combust. Inst. 36 (2017) $553-560$.

[5] W. Sun, B. Yang, N. Hansen, K. Moshammer, The influence of dimethoxy methane (DMM)/dimethyl carbonate (DMC) addition on a premixed ethane/oxygen/argon flame, Proc. Combust. Inst. 36 (2017) $449-457$.

[6] W. Sun, B. Yang, N. Hansen, C.K. Westbrook, F. Zhang, G. Wang, K. Moshammer, C.K. Law, An experimental and kinetic modeling study on dimethyl carbonate (DMC) pyrolysis and combustion, Combust. Flame 164 (2016) 224-238.

[7] A. Arteconi, A. Mazzarini, G. Di Nicola, Emissions from ethers and organic carbonate fuel additives: a review, Water Air Soil Pollut. 221 (2011) 405-423.

[8] Y. Ren, Z. Huang, H. Miao, Y. Di, D. Jiang, K. Zeng, B. Liu, X. Wang, Combustion and emissions of a DI diesel engine fuelled with diesel-oxygenate blends, Fuel 87 (2008) 2691-2697. 
[9] M. Kozak, J. Merkisz, P. Bielaczyc, A. Szczotka, The Influence of Synthetic Oxygenates on Euro IV

Diesel Passenger Car Exhaust Emissions-Part 3, Report No. 2008-01-2387, SAE Technical Paper, 2008.

[10] O. Arbeláez, A. Orrego, F. Bustamante, A.L. Villa, Direct Synthesis of Diethyl Carbonate from $\mathrm{CO}_{2}$ and $\mathrm{CH}_{3} \mathrm{CH}_{2} \mathrm{OH}$ Over $\mathrm{Cu}-\mathrm{Ni} / \mathrm{AC}$ Catalyst, Top. Catal. 55 (2012) 668-672.

[11] Z. Wang, H. Bian, Y. Wang, L. Zhang, Y. Li, F. Zhang, F. Qi, Investigation on primary decomposition of ethylcyclohexane at atmospheric pressure, Proc. Combust. Inst. 35 (2015) 367-375.

[12] H. Pines, W.O. Haag, Alumina: catalyst and support. I. alumina, its intrinsic acidity and catalytic activity1, J. Am. Chem. Soc. 82 (1960) 2471-2483.

[13] D. Maciver, H. Tobin, R. Barth, Catalytic aluminas I. Surface chemistry of eta and gamma alumina, $J$. Catal. 2 (1963) 485-497.

[14] Y. Zhang, J. Cai, L. Zhao, J. Yang, H. Jin, Z. Cheng, Y. Li, L. Zhang, F. Qi, An experimental and kinetic modeling study of three butene isomers pyrolysis at low pressure, Combust. Flame 159 (2012) 905-917.

[15] T.A. Cool, A. McIlroy, F. Qi, P.R. Westmoreland, L. Poisson, D.S. Peterka, M. Ahmed, Photoionization mass spectrometer for studies of flame chemistry with a synchrotron light source, Rev. Sci. Instrum. 76 (2005) 094102.

[16] N. Hansen, T.A. Cool, P.R. Westmoreland, K. Kohse-Höinghaus, Recent contributions of flame-sampling molecular-beam mass spectrometry to a fundamental understanding of combustion chemistry, Prog. Energ. Combust. 35 (2009) 168-191.

[17] H. Koizumi, Predominant decay channel for superexcited organic molecules, J. Chem. Phys. 95 (1991) $5846-5852$.

[18] J.C. Traeger, R.G. McLoughlin, A. Nicholson, Heat of formation for acetyl cation in the gas phase, J. Am. Chem. Soc. 104 (1982) 5318-5322.

[19] T.A. Cool, K. Nakajima, C.A. Taatjes, A. McIlroy, P.R. Westmoreland, M.E. Law, A. Morel, Studies of a fuel-rich propane flame with photoionization mass spectrometry, Proc. Combust. Inst. 30 (2005) 1681-1688. [20] A. Lucassen, N. Labbe, P.R. Westmoreland, K. Kohse-Höinghaus, Combustion chemistry and fuel-nitrogen conversion in a laminar premixed flame of morpholine as a model biofuel, Combust. Flame 158 (2011) 1647-1666. 
[21] M. Schenk, L. Leon, K. Moshammer, P. Oßwald, T. Zeuch, L. Seidel, F. Mauss, K. Kohse-Höinghaus,

Detailed mass spectrometric and modeling study of isomeric butene flames, Combust. Flame 160 (2013) 487-503.

[22] T. Tao, W. Sun, B. Yang, N. Hansen, K. Moshammer, C.K. Law, Investigation of the chemical structures of laminar premixed flames fueled by acetaldehyde, Proc. Combust. Inst. 36 (2017) 1287-1294.

[23] F.N. Egolfopoulos, N. Hansen, Y. Ju, K. Kohse-Höinghaus, C.K. Law, F. Qi, Advances and challenges in laminar flame experiments and implications for combustion chemistry, Prog. Energ. Combust. 43 (2014) $36-67$.

[24] R. Notario, J. Quijano, C. Sánchez, E. Vélez, Theoretical study of the mechanism of thermal decomposition of Carbonate esters in the gas phase, J. Phys. Org. Chem. 18 (2005) 134-141.

[25] R. Añez, A. Herize, A. Sierraalta, T. Cordova, G. Chuchani, DFT Study of substituent effects of 2 substituted alkyl ethyl methylcarbonates in homogeneous, unimolecular gas phase elimination kinetics, Int. J. Chem. Kinet. 38 (2006) 184-193.

[26] J. Herzler, J.A. Manion, W. Tsang, Single-pulse shock tube studies of the decomposition of ethoxy compounds, J. Phys. Chem. A 101 (1997) 5494-5499.

[27] B.P. Kar, N. Ramanathan, K. Sundararajan, K. Viswanathan, Matrix isolation and DFT study of the conformations of diethylcarbonate, J. Mol. Struct. 1072 (2014) 61-68.

[28] G. Knizia, T.B. Adler, H.-J. Werner, Simplified CCSD (T)-F12 methods: Theory and benchmarks, $J$. Chem. Phys. 130 (2009) 054104.

[29] M. Frisch, G. Trucks, H. Schlegel, G. Scuseria, M. Robb, J. Cheeseman, G. Scalmani, V. Barone, B. Mennucci, G. Petersson, Gaussian 09, Revision D.01, Gaussian Inc.: Wallingford, CT, USA, 2009.

[30] H. Werner, P. Knowles, G. Knizia, F. Manby, M. Schütz, P. Celani, T. Korona, R. Lindh, A. Mitrushenkov, G. Rauhut, MOLPRO, version 2012.1, A Package of Ab Initio Programs, (http://www.molpro.net).

[31] Y. Georgievskii, J.A. Miller, M.P. Burke, S.J. Klippenstein, Reformulation and solution of the master equation for multiple-well chemical reactions, J. Phys. Chem. A 117 (2013) 12146-12154.; Y. Georgievskii and S. J. Klippenstein, MESS.12016.12143.12123. (http://tcg.cse.anl.gov/papr/codes/mess.html).

[32] C. Eckart, The penetration of a potential barrier by electrons, Phys. Rev. 35 (1930) 1303.

[33] C.L. Yaws, Thermophysical properties of chemicals and hydrocarbons, William Andrew, 2008. 
[34] S. Peukert, R. Sivaramakrishnan, J. Michael, High Temperature Shock Tube and Theoretical Studies on

the Thermal Decomposition of Dimethyl Carbonate and Its Bimolecular Reactions with H and D-Atoms, $J$. Phys. Chem. A 117 (2013) 3718-3728.

[35] L.S. Tran, J. Pieper, H.-H. Carstensen, H. Zhao, I. Graf, Y. Ju, F. Qi, K. Kohse-Höinghaus, Experimental and kinetic modeling study of diethyl ether flames, Proc. Combust. Inst. 36 (2017) 1165-1173.

[36] J. Mendes, C.-W. Zhou, H.J. Curran, Theoretical Study of the Rate Constants for the Hydrogen Atom Abstraction Reactions of Esters with OH Radicals, J. Phys. Chem. A 118 (2014) 4889-4899.

[37] J. Mendes, C.-W. Zhou, H.J. Curran, Theoretical and Kinetic Study of the Hydrogen Atom Abstraction Reactions of Esters with $\mathrm{HO}_{2}$ Radicals, J. Phys. Chem. A 117 (2013) 14006-14018.

[38] Q.D. Wang, X.J. Wang, Z.W. Liu, G.J. Kang, Theoretical and kinetic study of the hydrogen atom abstraction reactions of ethyl esters with hydrogen radicals, Chem. Phys. Lett. 616 (2014) 109-114.

[39] E. Zervas, Formation of organic acids from propane, isooctane and toluene/isooctane flames, Fuel 84 (2005) 691-700.

[40] F. Battin-Leclerc, A.A. Konnov, J.L. Jaffrezo, M. Legrand, To Better Understand the Formation of Short-Chain Acids in Combustion Systems, Combust. Sci. Technol. 180 (2007) 343-370.

[41] M. Christensen, A.A. Konnov, Laminar burning velocity of acetic acid+ air flames, Combust. Flame 170 (2016) 12-29.

[42] M. Cameron, V. Sivakumaran, T.J. Dillon, J.N. Crowley, Reaction between $\mathrm{OH}$ and $\mathrm{CH}_{3} \mathrm{CHO}$ Part 1. Primary product yields of $\mathrm{CH}_{3}(296 \mathrm{~K}), \mathrm{CH}_{3} \mathrm{CO}(296 \mathrm{~K})$, and H (237-296 K), Phys. Chem. Chem. Phys. 4 (2002) 3628-3638.

[43] K. Yasunaga, F. Gillespie, J. Simmie, H. Curran, Y. Kuraguchi, H. Hoshikawa, M. Yamane, Y. Hidaka, A multiple shock tube and chemical kinetic modeling study of diethyl ether pyrolysis and oxidation, J. Phys. Chem. A 114 (2010) 9098-9109.

[44] W.G. Mallard, P.J. Linstrom, NIST chemistry WebBook, NIST standard reference database number 69 (1998) http://webbook.nist.gov/chemistry/.

[45] R. Kee, F. Rupley, J. Miller, M. Coltrin, J. Grcar, E. Meeks, H. Moffat, A. Lutz, G. Dixon-Lewis, M. Smooke, CHEMKIN-PRO Release 15082, Reaction Design, Inc., San Diego, CA (2008). 
[46] U. Struckmeier, P. Oßwald, T. Kasper, L. Böhling, M. Heusing, M. Köhler, A. Brockhinke, K.

Kohse-Höinghaus, Sampling probe influences on temperature and species concentrations in molecular beam mass spectroscopic investigations of flat premixed low-pressure flames, Z. Phys. Chem. 223 (2009) 503-537. [47] X. Lu, D. Han, Z. Huang, Fuel design and management for the control of advanced compression-ignition combustion modes, Prog. Energ. Combust. 37 (2011) 741-783.

[48] H. O'Neal, S. Benson, A Method for estimating the Arrhenius A factors for four-and six-center unimolecular reactions, J. Phys. Chem 71 (1967) 2903-2921.

[49] W. Ren, R. Mitchell Spearrin, D.F. Davidson, R.K. Hanson, Experimental and modeling study of the thermal decomposition of C3-C5 ethyl esters behind reflected shock waves, J. Phys. Chem. A 118 (2014) 1785-1798.

[50] B. Akih-Kumgeh, J.M. Bergthorson, Experimental and modeling study of trends in the high-temperature ignition of methyl and ethyl esters, Energ. Fuel 25 (2011) 4345-4356.

[51] P.A. Glaude, W.J. Pitz, M.J. Thomson, Chemical kinetic modeling of dimethyl carbonate in an opposed-flow diffusion flame, Proc. Combust. Inst. 30 (2005) 1111-1118.

[52] C.K. Westbrook, Biofuels Combustion, Annu. Rev. Phys. Chem. 64 (2013) 201-219.

[53] D.A. Good, J.S. Francisco, Tropospheric Oxidation Mechanism of Dimethyl Ether and Methyl Formate, J. Phys. Chem. A 104 (2000) 1171-1185.

[54] L.R. McCunn, K.-C. Lau, M.J. Krisch, L.J. Butler, J.-W. Tsung, J.J. Lin, Unimolecular dissociation of the $\mathrm{CH}_{3} \mathrm{OCO}$ radical: an intermediate in the $\mathrm{CH}_{3} \mathrm{O}+\mathrm{CO}$ reaction, J. Phys. Chem. A 110 (2006) 1625-1634.

[55] L.K. Huynh, K.C. Lin, A. Violi, Kinetic modeling of methyl butanoate in shock tube, J. Phys. Chem. A 112 (2008) 13470-13480.

[56] L. Zhao, M. Xie, L. Ye, Z. Cheng, J. Cai, Y. Li, F. Qi, L. Zhang, Corrigendum to "An experimental and modeling study of methyl propanoate pyrolysis at low pressure" [Combust. Flame 160 (2013) 1958-1966], Combust. Flame 161 (2014) 631-632.

[57] Y.R. Luo, Handbook of bond dissociation energies in organic compounds, CRC Press, 2003. 
Figures and schemes:<smiles>COC(=O)O[Tl]</smiles>

dimethyl carbonate (DMC)<smiles>CCOC(=O)OCC</smiles>

diethyl carbonate (DEC)

Scheme 1. Chemical structures of dimethyl carbonate (DMC) and diethyl carbonate (DEC).

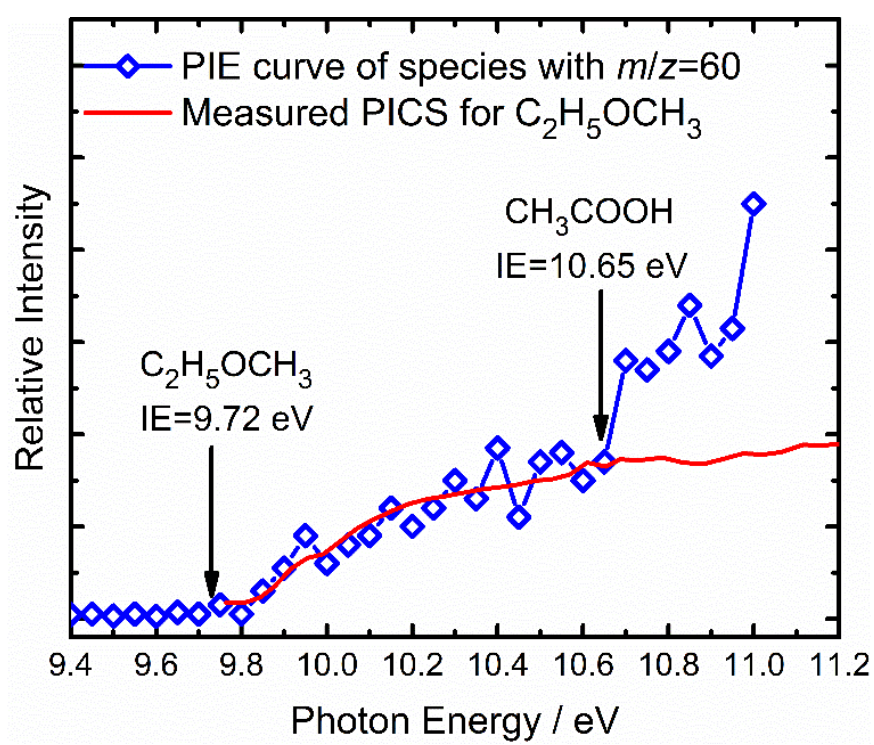

Fig. 1. The PIE curve for species with $\mathrm{m} / \mathrm{z}=60$ in the DEC flame at $3.0 \mathrm{~mm}$ away from the burner and the photoionization cross section (PICS) for $\mathrm{C}_{2} \mathrm{H}_{5} \mathrm{OCH}_{3}$ reported in literature [17], with photon energy ranging from 9.4 to $11.2 \mathrm{eV}$.

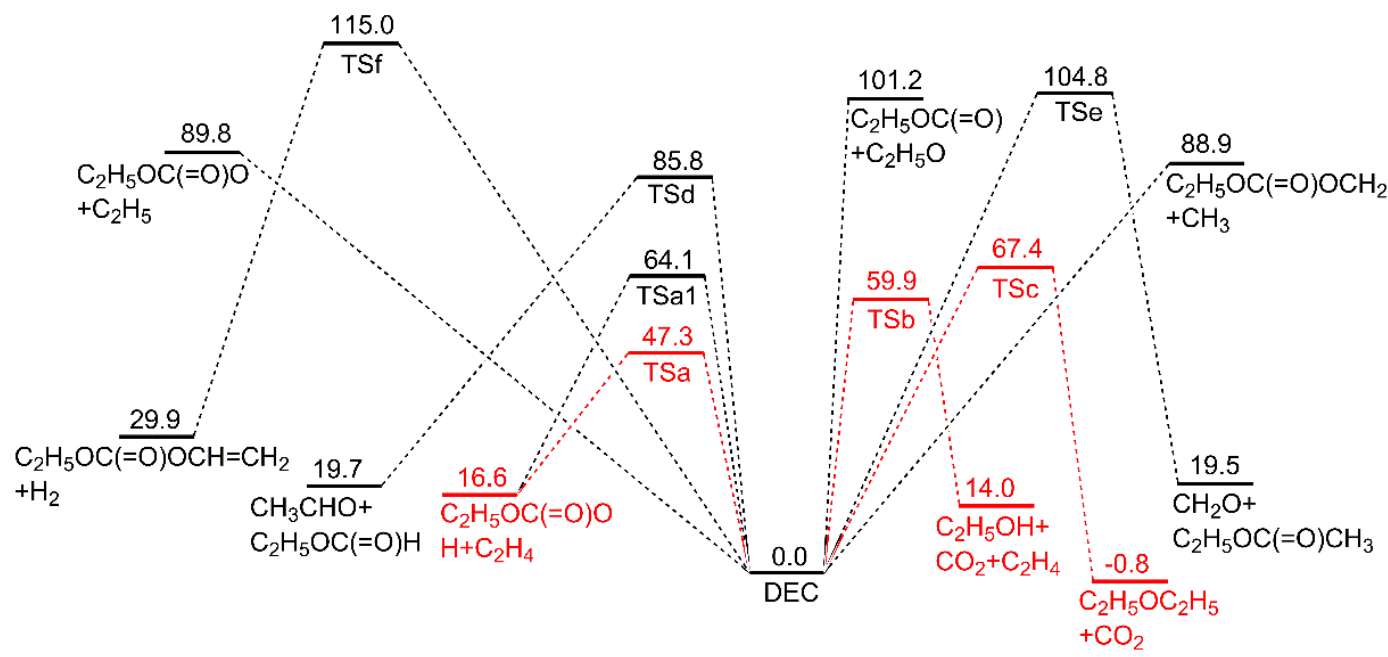

Fig. 2. The potential energy surface (PES) for DEC decompositions at the CCSD(T)-F12/cc-pVTZ-F12//B3LYP/cc-pVTZ level of theory. (Unit, kcal/mol) 


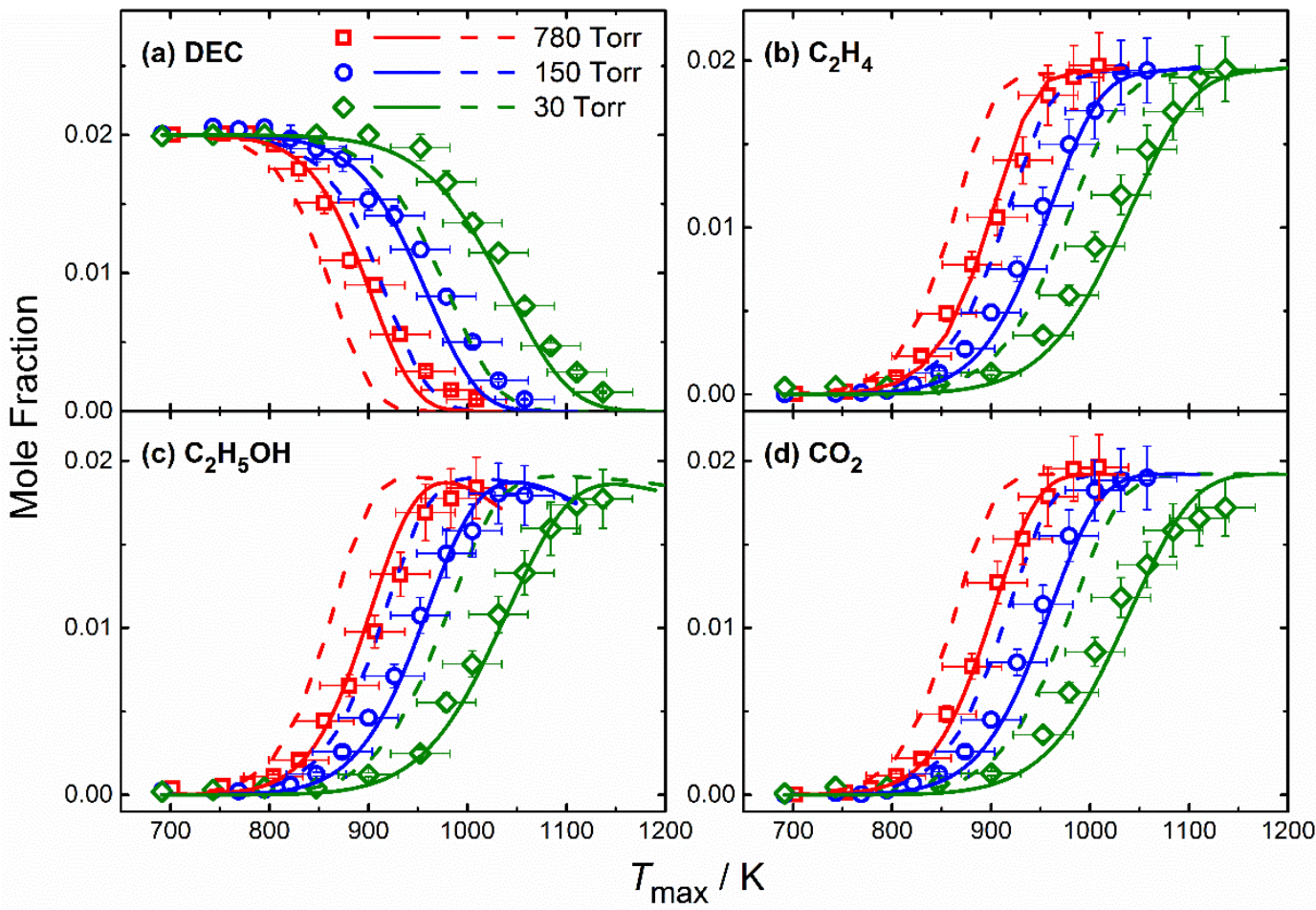

Fig. 3. Experimental mole fraction profiles (symbols) and modeling results (lines) of DEC, $\mathrm{C}_{2} \mathrm{H}_{4}, \mathrm{C}_{2} \mathrm{H}_{5} \mathrm{OH}$, and $\mathrm{CO}_{2}$ during $\mathrm{DEC}$ pyrolysis in a laminar flow reactor at various pressures. Solid lines: the modified model; dashed lines: the original model from [3].
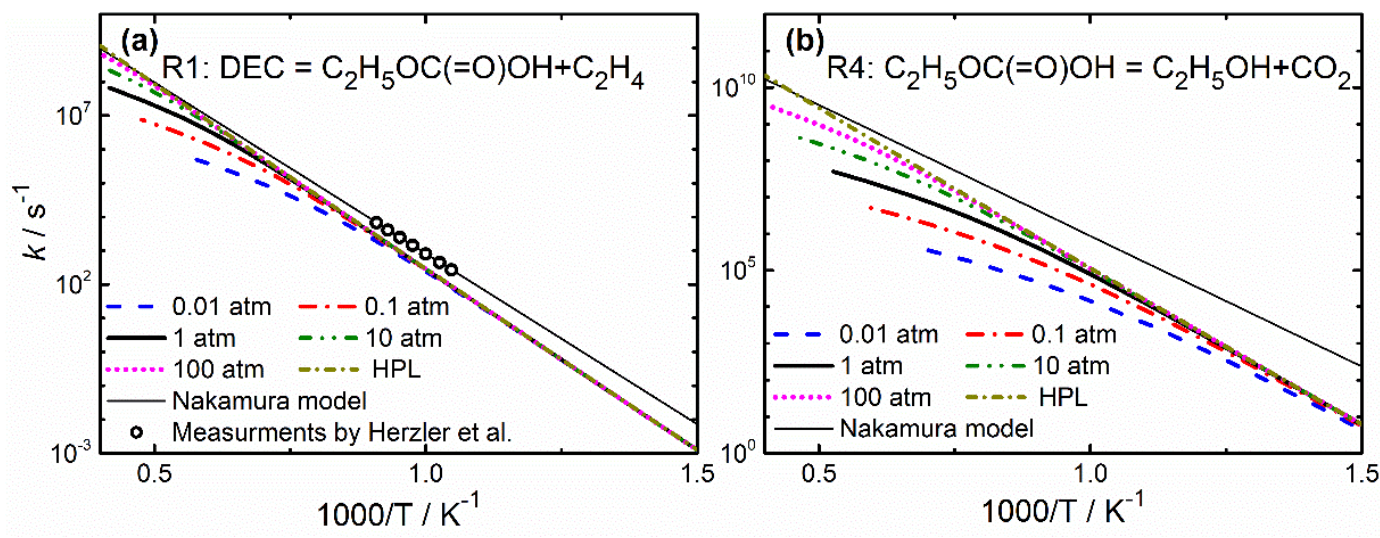

Fig. 4. Comparisons of the rate coefficients for (a) R1: $\mathrm{DEC}=\mathrm{C}_{2} \mathrm{H}_{5} \mathrm{OC}(=\mathrm{O}) \mathrm{OH}+\mathrm{C}_{2} \mathrm{H}_{4}$ and (b) $\mathrm{R} 4$ : $\mathrm{C}_{2} \mathrm{H}_{5} \mathrm{OC}(=\mathrm{O}) \mathrm{OH}=\mathrm{C}_{2} \mathrm{H}_{5} \mathrm{OH}+\mathrm{CO}_{2}$. Thick lines: calculated pressure-dependent results in the present work; Thin lines: the values adopted in the model by Nakamura et al. [3]; Symbols: measurements for $k_{1}$ reported in Herzler et al. [26] (2.0-4.0 bar) . 


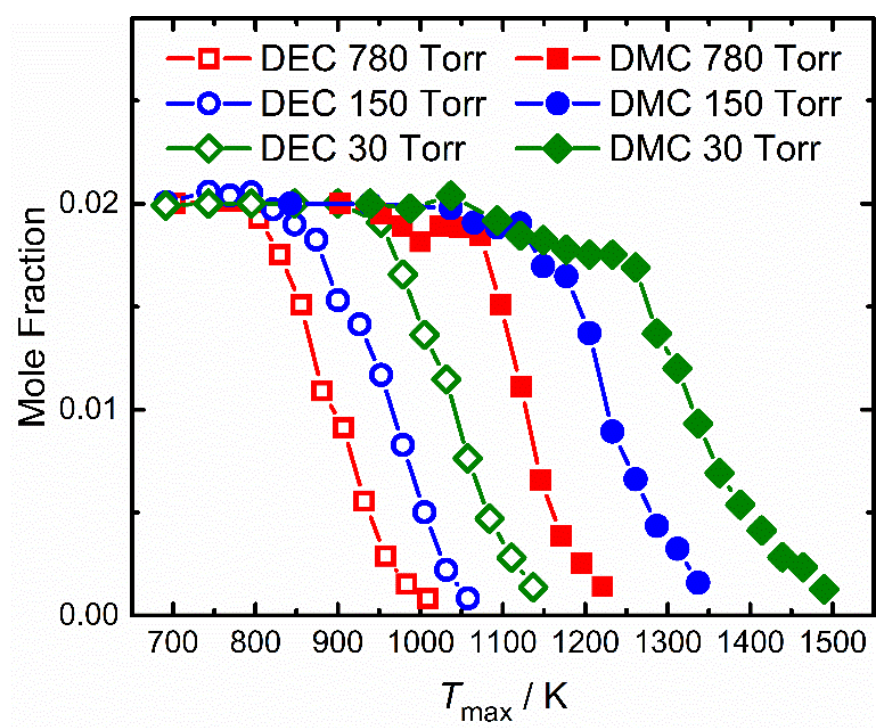

Fig. 5. Measured fuel mole fractions as functions of $T_{\max }$ in DMC [6] and DEC pyrolysis under different pressures.

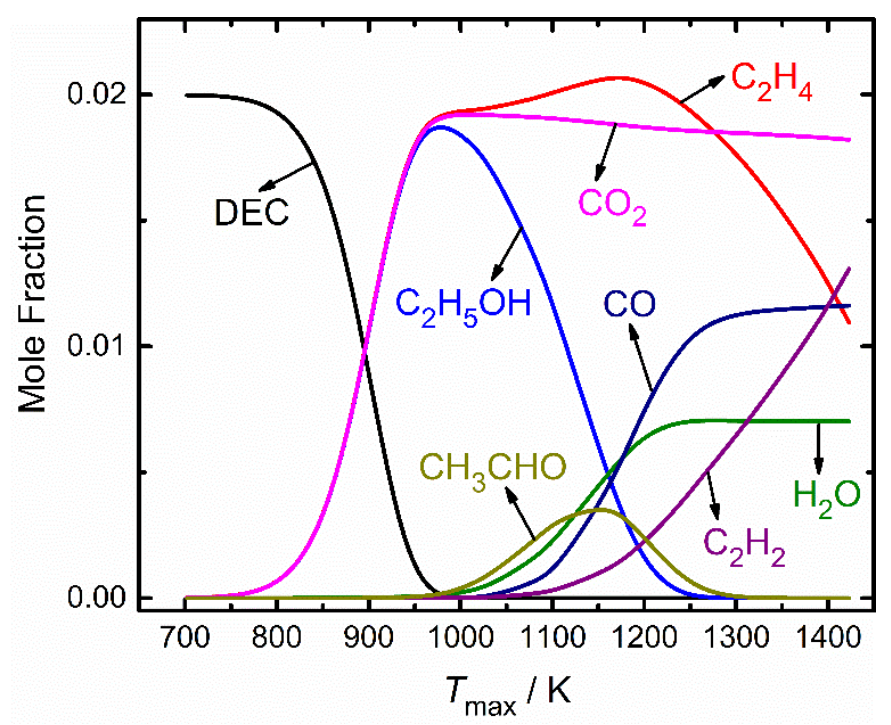

Fig. 6. Simulated species mole fraction profiles in an extended temperature range under the pressure of 780 Torr. 


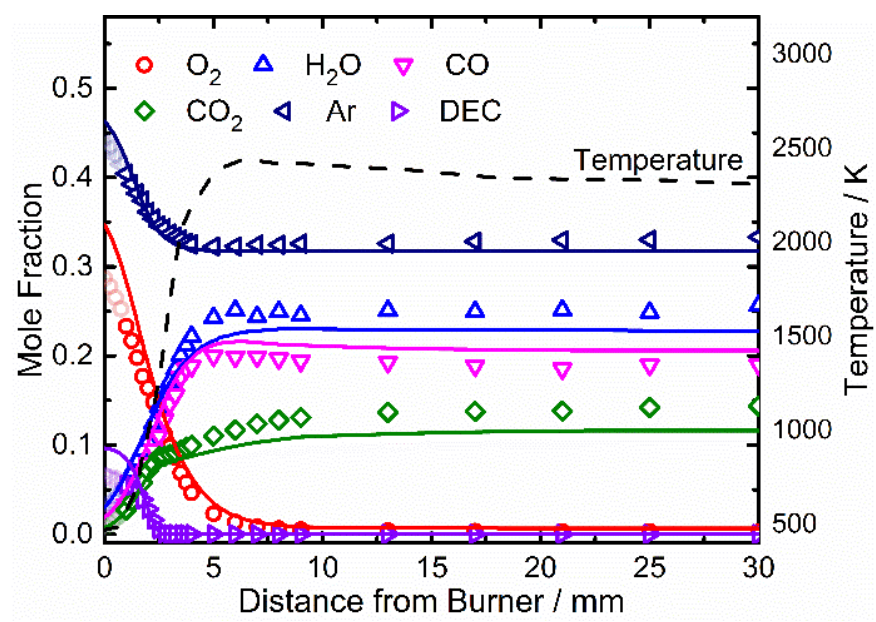

Fig. 7. Experimental mole fraction profiles (symbols) and modeling results (solid lines) of major species in the premixed DEC flame. Dashed lines: the measured temperature profile.
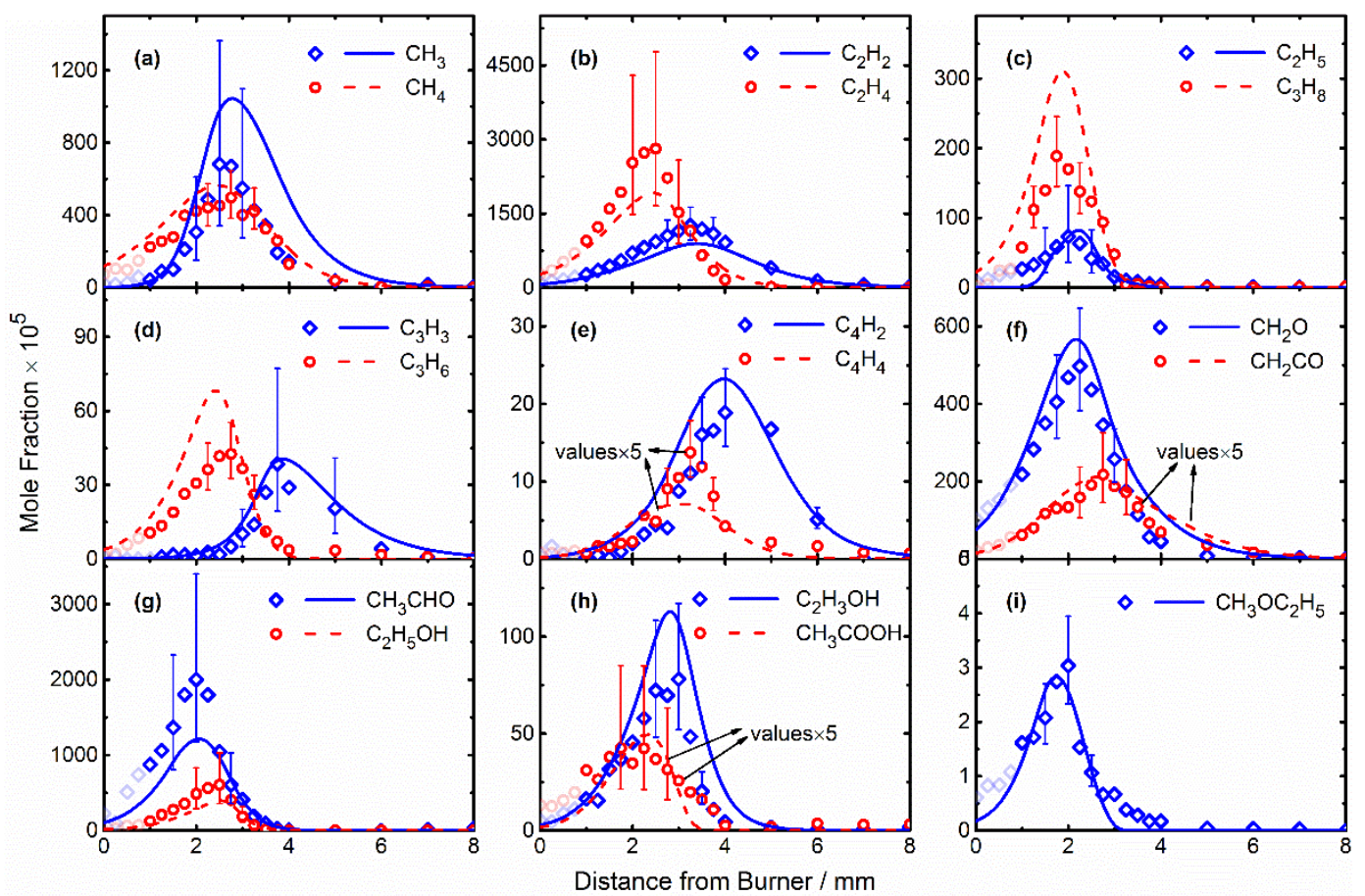

Fig. 8. Experimental (symbols) and simulated (lines) mole fraction profiles of some crucial intermediates in the premixed DEC flame. Error bars: uncertainty bars of the measurements. 
<smiles>CCOC(=O)O[14CH2]C</smiles><smiles>CCOC(=O)OC(C)CC</smiles>
$-\mathrm{CH}_{3} \mathrm{CHO}$ $100 \%$<smiles>CCOC=O</smiles>

$\mathrm{C}_{2} \mathrm{H}_{5} \mathrm{O} \dot{\mathrm{C}}(=\mathrm{O})$

$-\mathrm{CO}_{2}$

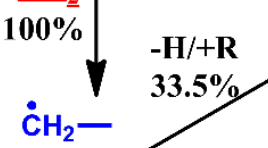

$\mathrm{C}_{2} \mathrm{H}_{5}$

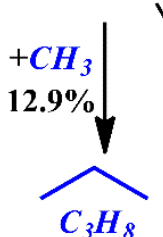

$\downarrow$

$C_{3}$ hydrocarbons

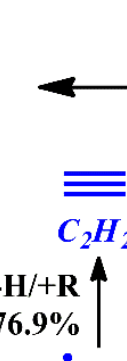

$+\mathbf{R}$

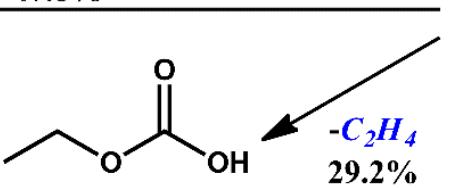<smiles>CCOC(=O)OCC</smiles>

DEC

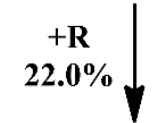<smiles>CCC(=[OH+])O[Na]</smiles>
$-\frac{\mathrm{CO}_{2}}{95.1 \%}$

$\mathrm{C}_{2} \mathrm{H}_{3}$

$+\mathrm{R} \uparrow$

$82.8 \%$

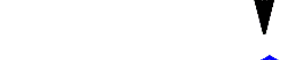
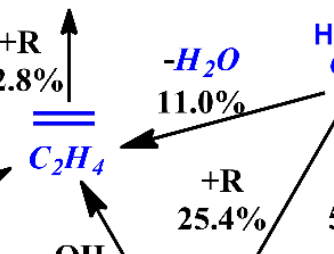

$\mathrm{C}_{2} \mathrm{H}_{5} \mathrm{OH}$<smiles>CCOC(=O)OCCOCCOC(=O)OCC</smiles>

$1.7 \%$<smiles>CCCO</smiles>
$\mathrm{PC}_{2} \mathrm{H}_{4} \mathrm{OH}$

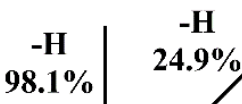

$\mathrm{SC}_{2} \mathrm{H}_{4} \mathrm{OH}$

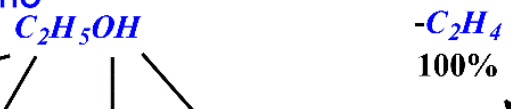

$100 \%$<smiles>CCOC(=O)O</smiles><smiles>CCOC(=[18O])OCC</smiles>

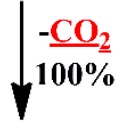<smiles>CCCCC(C)C</smiles>

$\mathrm{O}=\mathrm{CH}_{2}$

$\mathrm{CH}_{2} \mathrm{O}$

Fig. 9. Reaction pathways for DEC in the premixed flame based on the integrated ROP analysis along the entire flame. The numbers are percent contribution to the consumption of the species on the source side and the highlighted species (marked in italic) were measured in the present experiments.

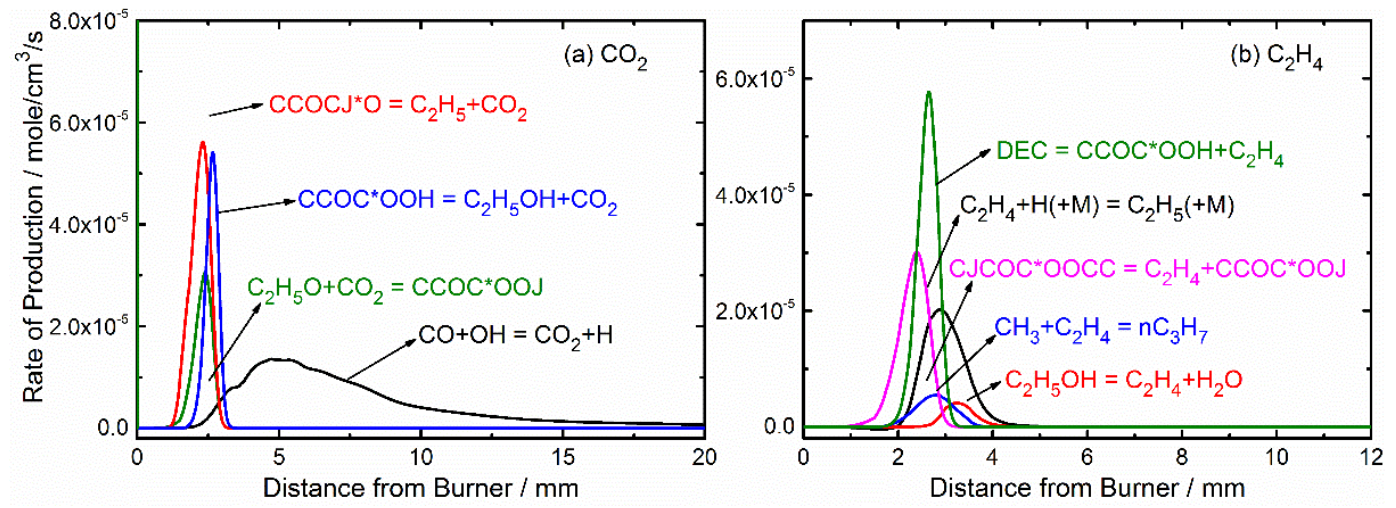

Fig. 10. ROP analysis (left axis) and for (a) $\mathrm{CO}_{2}$ and (b) $\mathrm{C}_{2} \mathrm{H}_{4}$ along the distance from burner in the DEC premixed flame. 


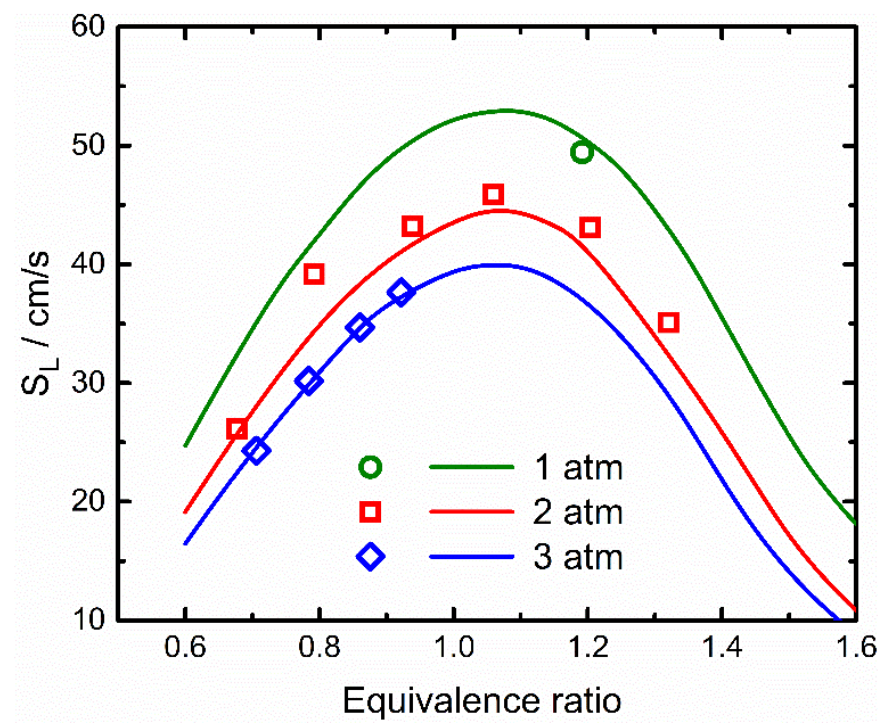

Fig. 11. Experimental [4] (symbols) and simulated burning velocities of DEC/air at $393 \mathrm{~K}$.<smiles>CCOC(=O)OCC</smiles><smiles>CCOC(=O)OCC</smiles><smiles>[R]C(=O)OCC</smiles>
ethyl esters<smiles>[R]OC(=O)O[Na]</smiles><smiles>CCOC(=O)OCC</smiles><smiles>[R]OCC</smiles>

Scheme 2. Oxygenated moieties imbedded in DEC and other molecules of different categories. 